ESTUDIOS 



\title{
LA CRISIS DE LA DEMOCRACIA PARLAMENTARIA. EL CASO DE LA COVID-19
}

\author{
JAVIER BARNES \\ Universidad Pompeu Fabra
}

Cómo citar/Citation

Barnes, J. (2021).

La crisis de la democracia parlamentaria. El caso de la COVID-19.

Revista de Administración Pública, 216, 101-139.

doi: https://doi.org/10.18042/cepc/rap.216.04

\section{Resumen}

A las Cortes Generales les corresponde establecer el marco legislativo adecuado para habilitar, condicionar y controlar el ejercicio de los poderes de emergencia que se le atribuyen al Ejecutivo, bien sean estos de carácter ordinario o bien extraordinario $-\mathrm{y}$ que pueden afectar no solo a los derechos fundamentales, sino también al sistema de fuentes del derecho y al orden de distribución de competencias, entre otros impactos - . Sin embargo, la resistencia parlamentaria a aprobar una verdadera ley contra las enfermedades contagiosas o infecciosas se encuentra en la base del conflicto, no solo en el período de "entre alarmas» o de "post-alarma», sino durante su misma vigencia.

La abdicación constitucional de la «potestad legislativa del Estado» (art. 66.2 $\mathrm{CE}$ ) en este punto causa la desprotección de los derechos, quiebra principios básicos como el Estado democrático de derecho y genera innecesariamente otros graves problemas constitucionales, al forzar el uso de una infraestructura legal manifiestamente incapaz de soportar el peso. Entre esas derivadas, destaca la externalización del coste político que han de asumir las Cortes y el Gobierno en la lucha contra la pandemia hacia los jueces.

\section{Palabras Clave}

Democracia parlamentaria; principio de legalidad y reserva de ley; estado de alarma y poderes extraordinarios; derechos fundamentales; legitimación democrática 
del Ejecutivo y de la Administración; incumplimiento del deber de legislar; división de poderes.

\begin{abstract}
It is the responsibility of parliament under constitutional principles to enact an act providing the powers - ordinary and extraordinary - to be given to the executive in the fight against contagious diseases. Extraordinary emergency powers - exercised through regulations according to such act - can affect fundamental rights, sources of the law and allocation of competences in a multilevel system. Hence the need, firstly, for such an act to meet special requirements and, secondly, for an intense parliamentary scrutiny. If parliament fails in this twofold mission, first and foremost in the comprehensive regulation of those powers with due safeguards, it creates other serious consequential constitutional concerns and a severe democratic deficit.
\end{abstract}

\title{
Keywords
}

Parliamentary democracy; principle of legality; delegation of legislative power; state of (health) emergency and emergency powers; fundamental rights; democratic legitimation of the Executive and the Administration; breach of the duty to legislate; separation of powers. 


\section{SUMARIO}

I. INTRODUCCIÓN: EL DEBATE EN CONTEXTO: 1. Objeto: el principio de legalidad y la reserva de ley en la lucha contra las enfermedades contagiosas: 1.1. Estado de alarma vs. legislación sanitaria. Habilitación legislativa y regulación legal. 1.2. El problema de la ausencia de una ley general contra enfermedades infecciosas. 1.3 Tesis que se postula. 2. Delimitaciones necesarias para apreciar las exigencias del principio de legalidad y de la reserva de ley: 2.1. La distinción entre emergencia ordinaria y emergencia extraordinaria. 2.2. La distinción entre potestades ordinarias y potestades extraordinarias. 2.3. La distinción entre restricciones singulares y restricciones de carácter general, entre el control de enfermos y el control de personas sanas. 2.4. La distinción entre la actividad administrativa de policía sanitaria y los poderes de emergencia extraordinaria; entre la historia de la legislación de salud pública y el Estado constitucional de Derecho. 2.5. La distinción entre las declaraciones formales de emergencia (extraordinaria) y su efectivo ejercicio fuera de tales declaraciones. 3. Un resumen sobre la distinción entre el Derecho ordinario y el extraordinario. II. LA ABDICACIÓN DE LA «FUNCIÓN LEGISLATIVA DEL ESTADO» (ARTICULO 66.2 CE): 1. Las diversas opciones del legislador estatal. 2. El problema constitucional de fondo: 2.1. La resistencia de las Cortes a aprobar un Derecho extraordinario de emergencia sanitaria. 2.2. La externalización del coste político de la lucha contra la pandemia hacia las Comunidades Autónomas y los jueces. 3. Problemas constitucionales derivados en períodos de «entre alarmas» y de «post-alarma». 4. ¿Remedios jurídicos directos frente a la inactividad parlamentaria? La experiencia comparada. III. UNA MIRADA COMPARADA SOBRE EL PRINCIPIO DE LEGALIDAD EN LA LUCHA CONTRA EL COVID-19: 1. Reino Unido: 1.1. Introducción. La infraestructura legal previa a la pandemia del Covid-19: Ley de Salud Pública para el Control de Enfermedades (1984) y la Ley de Emergencias Civiles (2004). 1.2. La Ley del Coronavirus de 2020. 2. Alemania: 2.1. Introducción. La infraestructura legal previa a la pandemia del Covid-19: la Ley Federal contra las enfermedades contagiosas. 2.2. Potestades ordinarias y extraordinarias en la LEC. 3. Un balance sobre el principio de legalidad en la lucha contra la pandemia. IV. LA QUIEBRA DEL PRINCIPIO DE LEGALIDAD Y DE LA RESERVA DE LEY EN EL ORDENAMIENTO ESPAÑOL EN LA LUCHA CONTRA EL COVID-19: 1. La ausencia de una ley de lucha contra las enfermedades contagiosas: 1.1. Inexistencia de una ley de emergencia extraordinaria que se integre con el estado de alarma. 1.2. Manifiesta insuficiencia del Derecho ordinario contra las enfermedades infecciosas. 2. La jurisprudencia del Tribunal Supremo en «casación» sobre ratificación de medidas de carácter general. V. UNA REFLEXIÓN FINAL. LA CRISIS DE LA DEMOCRACIA PARLAMENTARIA. 
El principio de legalidad significa que el Parlamento debe enfrentarse directamente a lo que hace y asumir el coste político que ello implica. En ese sentido, los derechos fundamentales no pueden ser ignorados mediante palabras generales o ambiguas. Y ello se debe a que es muy alto el riesgo de que las consecuencias de una previsión inespecífica y no delimitada pasen inadvertidas en el proceso democrático. Por tanto, a falta de una previsión expresa o de una implicación necesaria en sentido contrario, los tribunales presumirán que hasta las más genéricas expresiones de la ley nacen con la intención de estar sujetas y subordinadas a los derechos fundamentales del individuo. De este modo, los tribunales del Reino Unido, aunque reconocen la soberanía del Parlamento, siguen este principio constitucional no escrito que poco se diferencia de los Estados dotados de Constitución escrita. (House of Lords) ${ }^{1}$.

\section{INTRODUCCIÓN: EL DEBATE EN CONTEXTO}

\section{OBJETO: EL PRINCIPIO DE LEGALIDAD Y LA RESERVA DE LEY EN LA LUCHA CONTRA LAS ENFERMEDADES CONTAGIOSAS}

\subsection{Estado de alarma vs. legislación sanitaria. Habilitación legislativa y regula- ción legal}

Las páginas que siguen reflexionan sobre la dialéctica «alarma-legislación sanitaria ${ }^{2}$, esto es, en primer término sobre la cobertura formal de las medidas del Ejecutivo y de la Administración en la lucha contra la COVID-19: si solo

1 Cfr. Lord Hoffmann, en $R v$ Secretary of State for the Home Department, ex parte Simms [1999] UKHL 33. Se trata de un caso constitucional en Gran Bretańa, concerniente a la soberanía del parlamento y el principio de legalidad en relación con los derechos fundamentales. Se ofrece una traducción literaria, no literal, y resumida, aunque fiel a la argumentación.

Expresado en términos generales: es doctrina común que los poderes de emergencia capaces de restringir los derechos fundamentales — con alcance singular o general— han de ser atribuidos expresa y específicamente en la ley.

Para la interpretación de esta doctrina, a propósito de la lucha contra la pandemia, baste la remisión a la conferencia de Lord Sumption, profesor emérito y antiguo magistrado de la Supreme Court of the United Kingdom, "Government by decree - Covid-19 and the Constitution", pronunciada el 27 de octubre de 2020 (disponible en YouTube: https://bit. ly/3xlCtz1, última visita junio de 2021).

Téngase en cuenta que esta conocida doctrina — considerada la mejor formulación del principio de legalidad en la materia - ha sido recordada en Reino Unido en relación con un precepto - el art. 45C(1) de la Ley de 1984_, más concreto que los nuestros (nota 5), para concluir que no puede habilitar un confinamiento generalizado de personas sanas.

2 Fuera de nuestra atención queda la dialéctica «alarma-excepción», en cierto modo de menor entidad y consecuencias prácticas en términos comparativos desde la perspectiva que aquí se considera. 
tienen amparo en la previa declaración del estado de alarma (art. 116 CE y Ley Orgánica 4/1981, de 1 de junio, de los estados de alarma, excepción y sitio, en adelante LOAES), o también, y para análogas restricciones, en ciertos preceptos de la legislación sanitaria, sin necesidad de esa declaración.

La cuestión no termina, sin embargo, con la mera habilitación legislativa (cómo obtener la luz verde), sino que se extiende inescindiblemente al marco o regulación legal en que esa acción ha de moverse en la lucha contra la pandemia (concedido el permiso, qué cabe hacer).

\subsection{El problema de la ausencia de una ley general contra enfermedades infecciosas}

El hecho de que nuestro ordenamiento jurídico carezca de una ley general contra las enfermedades infecciosas en la que, de un lado, la acción administrativa pueda hallar parámetros materiales, organizativos y procedimentales, y, de otro, el Parlamento y los jueces criterios de control, genera otros problemas relacionados: a) en los períodos cubiertos por el estado de alarma, la ausencia de una ley a la que remitirse (art. 12.1 LOAES) obliga al Ejecutivo a «inventar» para cada tiempo y lugar las medidas extraordinarias adecuadas; y b) y en los períodos no cubiertos, tal ausencia apenas permite ejercer algunas potestades ordinarias frente a la COVID-19, ya que, como habrá ocasión de abundar, el art. 3 de la Ley Orgánica 3/1986, de 14 de abril, de Medidas Especiales en Materia de Salud Pública (en adelante, Ley 3/1986), por sí mismo no prevé expresas restricciones sobre derechos fundamentales, ni, menos aún, para toda la población.

En relación con este último supuesto, al que se contrae el caso contemplado en el presente artículo, el centro del problema se sitúa, pues, en el principio de legalidad $^{3}$ (fortalecido en los aspectos que ahora se tratan por la reserva de ley) ${ }^{4}$, y puede expresarse en un primer y elemental interrogante: en ausencia de una declaración de alarma ¿̇satisface nuestra legislación sanitaria vigente —en la lucha contra las enfermedades infecciosas - los requerimientos de tal principio? Esa genérica cuestión podría diseccionarse a su vez en otras dos: 1) ¿se observan el principio de legalidad y la reserva de ley cuando se aplica esa legislación sanitaria en la excepcionalidad pero sin la cobertura del estado de alarma?; y 2) jse cumplen al menos en lo que respecta al ejercicio de potestades administrativas ordinarias y al establecimiento de medidas restrictivas de carácter singular?

Tampoco entra en el foco de atención el análisis de las distintas posiciones doctrinales sobre aspectos puntuales. Lo que interesa aquí es la visión de conjunto de los efectos que una legislación insuficiente de esta naturaleza produce, así como su dimensión constitucional y comparada, teniendo en cuenta el telón de fondo de la crisis de la democracia parlamentaria (I.1.3, I.2 y V).

3 Arts. 1.1, 9.1, 53.1, 97 in fine, 103.1 in fine CE (véase nota siguiente).

4 Arts. 1.1 (principio democrático y principio de Estado de derecho), 53.1, 81, 116 CE. 


\subsection{Tesis que se postula}

Aquí se argumenta, primero, que la legislación sanitaria vigente — simbolizada en la Ley $3 / 1986)^{5}$ — no da cobertura al ejercicio de poderes de emergencia extraordinarios, sino tan solo a ciertas medidas sanitarias de ordinaria administración ${ }^{6} ; \mathrm{y}$, segundo, que la resistencia de las Cortes Generales a establecer la necesaria infraestructura legal supone una insólita y grave abdicación de la función legislativa del Estado ${ }^{7}$, con perniciosos efectos multiplicadores de orden constitucional. Más allá de la COVID-19, en segundo plano se advierte el problema subyacente y principal: la crisis de la democracia parlamentaria que deriva del déficit legislativo, así como las múltiples disfunciones orgánicas y estructurales que ello entraña.

Naturalmente, esta tesis requiere ser puesta en su debido contexto ${ }^{8}$. En tal sentido, resulta obligado: 1) diferenciar entre emergencias sanitarias ordinarias y

5 Recuérdese que el referido precepto dispone: «Con el fin de controlar las enfermedades transmisibles, la autoridad sanitaria, además de realizar las acciones preventivas generales, podrá adoptar las medidas oportunas para el control de los enfermos, de las personas que estén o hayan estado en contacto con los mismos y del medio ambiente inmediato, así como las que se consideren necesarias en caso de riesgo de carácter transmisible».

A este precepto se suman el art. 26 de la Ley 14/1986, y el art. 54 de la Ley 33/2011, cuyas previsiones -interpretadas de forma literal, sistemática, finalista, histórica y a la luz de la mens legislatoris - se mueven en la lógica tradicional, a saber: actuaciones limitadas en el tiempo y en el espacio, dirigidas esencialmente frente a personas contagiadas o sospechosas de estarlo, a cosas e instalaciones relacionadas (el art. 3 Ley 3/1986 habla por ello de "control de los enfermos" y de las personas que han estado en contacto). Se sitúan estas leyes en el ámbito de las potestades ordinarias y, como se desprende con naturalidad de su tenor literal, no autorizan a alterar el sistema de fuentes, el orden competencial, ni confinamientos preventivos de toda la población, lo que incluye obviamente a la sana.

Téngase en cuenta que el precitado art. 26 de la Ley 14/1986 alude a medidas preventivas, tales como la incautación o inmovilización de productos, suspensión del ejercicio de actividades, cierres de empresas o sus instalaciones, o intervención de medios materiales y personales. Por su parte, el art. 54 de la Ley 33/2011 hace referencia a medidas tales como la inmovilización y, si procede, el decomiso de productos y sustancias; la intervención de medios materiales o personales; el cierre preventivo de las instalaciones, establecimientos, servicios e industrias; la suspensión del ejercicio de actividades; la determinación de condiciones previas en cualquier fase de la fabricación o comercialización de productos y sustancias, así como del funcionamiento de las instalaciones, establecimientos, servicios e industrias a que se refiere esta ley.

6 El art. 3 Ley 3/1986 por sí mismo no da cobertura propiamente tampoco a restricciones singulares, si no es en relación con los escasos supuestos que contemplan las normas citadas en el segundo párrafo de la nota anterior. Tal precepto no suma, ni añade nada (véase el epígrafe IV.1). En contra la jurisprudencia del Tribunal Supremo (IV.2).

7 Art. 66.2 CE.

8 I.2, II, III. 
extraordinarias, entre Derecho ordinario y Derecho extraordinario'; 2) advertir que el ejercicio de poderes extraordinarios por parte del Ejecutivo - en cualesquiera de sus modalidades - impacta no ya solo sobre los derechos fundamentales y, en general, sobre la esfera de la libertad, sino también sobre el sistema de fuentes del derecho y el orden competencial entre los distintos niveles de gobierno $^{10}$; 3) mostrar que las Cortes Generales podían — y debían- legislar ${ }^{11}$; y 4) observar a algunos países de nuestro entorno para comprender la distancia que nos separa en el entendimiento que se ha hecho del principio de legalidad y de la reserva de ley ${ }^{12}$.

\section{DELIMITACIONES NECESARIAS PARA APRECIAR LAS EXIGENCIAS DEL PRINCIPIO DE LEGALIDAD Y DE LA RESERVA DE LEY}

El debate «alarma-legislación sanitaria» ha de sustraerse a la visión de túnel. A tal propósito, conviene considerar las siguientes diferencias o matices:

\subsection{La distinción entre emergencia ordinaria y emergencia extraordinaria}

Se debe discriminar de entrada entre lo que aquí llamamos - a efectos expositivos - la "emergencia extraordinaria» y la «emergencia ordinaria» o de «ordinaria administración».

Por decirlo en términos epidemiológicos: no es lo mismo una epidemia de gripe estacional o de tifus, que la COVID-19; o el confinamiento de pequeñas comunidades para "el control de los enfermos, de las personas que estén o hayan estado en contacto con los mismos y del medio ambiente inmediato» ${ }^{13}$ que el confinamiento generalizado de la población de un país con carácter preventivo. Mientras la primera se puede enfrentar con poderes ordinarios, la segunda altera por completo la vida del Estado y de la sociedad, y exige la activación de poderes extraordinarios en favor del Ejecutivo con las máximas garantías e intervención parlamentaria. El Derecho no es, no puede ser, el mismo para ambos supuestos por razones elementales. A la primera situación por justa convención la llamamos aquí Derecho ordinario, y a la segunda, Derecho extraordinario. Para entendernos, algunos preceptos de la legislación sanitaria antes citados pertenecerían al primer grupo ${ }^{14}$; y el art. $116 \mathrm{CE}$, al segundo. El Derecho extraordinario (art. 116

\footnotetext{
I.2, IV.

10 I.2.1, IV.

11 II.

12 III.

13 Art. 3 Ley 3/1986.

14 Supra nota 5.
} 
CE) es subsidiario del Derecho ordinario ${ }^{15}$. En todo caso, la ley habrá de regular ambos derechos, con las correspondientes garantías ${ }^{16}$.

\subsection{La distinción entre potestades ordinarias y potestades extraordinarias}

Consecuentemente, ha de distinguirse entre una actuación limitada en el tiempo y en el espacio contra una enfermedad infecciosa que habitualmente reclama el ejercicio de potestades ordinarias ${ }^{17}$, y una política de Estado que afecta, nótese bien, a la libertad, al sistema de fuentes y al orden de distribución de competencias, entre otros efectos económicos, sociales y políticos de calado, lo que requiere el ejercicio de potestades extraordinarias ex art. $116 \mathrm{CE}$ (y su consiguiente habilitación y regulación legales). Porque, en efecto, la emergencia extraordinaria no solo reclama el precio de la libertad ${ }^{18}$, sino que altera el sistema de fuentes del derecho - baste notar que el reglamento de emergencia puede desplazar a las leyes y que su elaboración prescinde del procedimiento ordinario-, y es susceptible de modificar la organización administrativa y el orden de distribución de competencias ${ }^{19}$. Es esta una clave fundamental desde la que valorar tantas cuestiones ${ }^{20}$. Sea como fuere, las potestades ordinarias y las extraordinarias — estas de modo reforzado y con una participación especial

15 Si son suficientes el derecho y los poderes ordinarios en la lucha contra la enfermedad infecciosa, no procederá acudir al estado de alarma. En sentido análogo, en este punto, el dictamen del Consejo de Estado 213/2021, de 22 de marzo, sobre recurso de inconstitucionalidad contra determinados preceptos de la Ley de la Comunidad Autónoma de Galicia 8/2021, de Salud, núm. IV.

Más proscrita aún si cabe queda la situación contraria: ejercer poderes extraordinarios con la pretendida cobertura del derecho ordinario, que es lo sucedido en nuestro caso: Infra IV. Notas 3-4. Infra III-V.

17 Véanse los ejemplos del art. 54 de la Ley 33/2011 (nota 5).

18 Constituye el aspecto más visible y conocido. La pérdida no se produce solo a consecuencia de las limitaciones, restricciones graves o eventuales suspensiones de los derechos fundamentales - la joya de la corona - sean estas a título individual o generalizado, sino de otros muchos derechos - la mayoría - de configuración legal. No es solo fruto de restricciones episódicas o puntuales, sino en ocasiones sistémicas y de larga duración. No se genera solo a resultas de una acción positiva, sino también de una insuficiente protección de ciertos derechos, como puede ser el derecho a la vida y a la integridad física y moral de todos, cualquiera que sea la edad y las circunstancias; o porque sea inadecuada la compensación arbitrada por la paralización de actividades económicas. $\mathrm{O}$ porque se active un régimen específico y distinto de un derecho fundamental —una nueva regulación-, como el de la protección de datos. Este impacto ha acaparado la atención. Pero no es el único.

19 P. ej.: desde el establecimiento de nuevas formas de coordinación o la eventual unidad de mando, pasando por la asunción de competencias locales por la instancia superior, hasta la creación de nuevas organizaciones, o la expansión horizontal de la competencia de salud pública.

Véase también III. 
del Parlamento para su activación temporal— han de establecerse mediante ley formal.

2.3. La distinción entre restricciones singulares y restricciones de carácter general, entre el control de enfermos y el control de personas sanas

Con frecuencia, las medidas singulares - dirigidas a un grupo determinado de individuos - suponen un ejercicio de potestades ordinarias, mientras que las medidas de alcance general se corresponden con el desempeño de potestades extraordinarias. Las singulares típicamente se proyecta de ordinario sobre personas contagiadas o sospechosas de estarlo; las generales, en cambio, de modo característico, pueden tener carácter preventivo y pueden afectar a personas sanas. No se trata, sin embargo, de una ecuación perfecta. De entrada, el binomio «medida singular-medida general» no equivale siempre al binomio "potestad ordinaria-potestad extraordinaria ${ }^{21}$. El deslinde entre la potestad ordinaria y la extraordinaria en última instancia no se deriva automáticamente del dato formal de la individualidad o de la generalidad de la injerencia, sino de la materialidad de los poderes efectivamente atribuidos en los términos antes indicados ${ }^{22}$.

En todo caso, las restricciones singulares y las restricciones generales — sean expresión o no de potestad ordinaria o extraordinaria- han de tener su base y regulación en la ley.

2.4. La distinción entre la actividad administrativa de policía sanitaria y los poderes de emergencia extraordinaria; entre la historia de la legislación de salud pública y el Estado constitucional de derecho

Una cosa es la normal actividad administrativa de policía (sanitaria), que se expresa tradicionalmente en limitaciones, órdenes, prohibiciones o reservas, predeterminadas en la ley, y otra, muy distinta, el ejercicio de poderes de emergencia extraordinarios ${ }^{23}$.

21 Por ejemplo, un precepto legal que regulara el cierre preventivo de instalaciones a consecuencia de una infección podría ser eventualmente implementado mediante reglamento (ejecutivo), con completa subordinación a la ley (y siempre que esta hubiera agotado la materia y habilitara el desarrollo reglamentario). Y en tal caso se trataría de reglamentos ordinarios, dirigidos a una pluralidad indeterminada de personas, en ejercicio de una potestad ordinaria, si bien limitados a desarrollar un precepto legal acotado. En cambio, un reglamento de emergencia sanitaria que pretenda desplazar a una ley — aun cuando no incida propiamente sobre un derecho fundamental - solo puede dictarse en ejercicio de potestades extraordinarias. Véanse III.2.2 y nota 130.

22 I.2.2 y nota anterior; infra I.3.

23 I.2.2. 
Como también es diferente lo que históricamente haya podido disponer la legislación contra las epidemias y lo que hoy puede prever en el marco de un Estado constitucional de Derecho ${ }^{24}$. El argumento histórico, obvio es decirlo, no legitima aquellas acciones — $\mathrm{u}$ omisiones - del legislador o del Ejecutivo de hoy que no cumplan con los presupuestos constitucionales ${ }^{25}$. De hecho, el art. 3 Ley 3/1986 evoca otros tiempos ${ }^{26}$.

Sean viejas o nuevas las medidas que quepa adoptar ${ }^{27}$, su régimen jurídico habrá de acomodarse igualmente a la Constitución y, en lo que ahora importa, al principio de legalidad y a la reserva de ley ${ }^{28}$.

24 Ciertamente, el derecho administrativo, como «ciencia de frontera», va por delante en muchos terrenos. No resulta extraño que los primeros tratados de derecho administrativo escritos en español se ocuparan de la lucha contra las epidemias. Por ejemplo, Manuel Colmeiro, Derecho Administrativo español, Madrid, 1850 (cfr. Biblioteca Digital Hispánica). Este autor sigue y cita a P. Gómez de la Serna, Instituciones de Derecho Administrativo, 1843. Si en el pasado un artículo como el 3 de la Ley 3/1986 pudo dar cobertura a injerencias singulares sobre derechos fundamentales, y aun a restricciones más amplias, hoy no resistiría el más mínimo análisis en el constitucionalismo occidental (III, IV).

Al fin y al cabo, la Constitución genera un efecto civilizador sobre el derecho administrativo, que, insertado en un específico hábitat constitucional, deja entonces de ser una mera tecnología jurídica al servicio del poder, para convertirse en "porteador» de los valores, bienes y derechos constitucionales hasta el último rincón de la acción administrativa.

Por ejemplo, la base 19a de la Ley de 25 de noviembre de 1944, de bases de la sanidad nacional, dispone que los gobernadores civiles «adoptarán en casos urgentes y bajo su responsabilidad las medidas necesarias que estimen convenientes para preservar la salud pública de epidemias, enfermedades contagiosas, focos de infección y otros riesgos análogos». Si nos retrotraemos aún más cabe advertir otros antecedentes. Así, por ejemplo, el art. 133 del proyecto de ley de Sanidad Civil de 1885 establecía que «el Gobierno, asesorado del Consejo, queda revestido de amplias facultades para disponer cuanto crea conveniente en los casos de epidemia» (Gaceta de Madrid, 81, de 22 de marzo). La Ley de Sanidad de 28 de noviembre de 1855 contiene disposiciones de ese estilo (arts. 58, 59, etc.).

27 Recuérdese que legislación administrativa contra las epidemias, en nuestro país y en los de nuestro entorno, se ha traducido históricamente en el confinamiento de las personas infectadas o sospechosas de contagio, no en el confinamiento preventivo de un país, como se ha producido con la COVID-19. Es algo nuevo confinar a personas sanas y a escala nacional. Acaso ese haya sido el reto principal al que se han enfrentado tantos Estados, aun cuando el derecho a la libre circulación se haya visto limitado de un modo menos severo que en nuestro caso (art. 7.1 RD 463/2020, de 14 de marzo; infra III). Sea como fuere, a la Constitución le resulta indiferente la denominación doctrinal (por ejemplo, de "policía administrativa", predicada de unas potestades y un ámbito del ordenamiento). De ello no depende la proyección de sus exigencias. De hecho alguna doctrina alemana inscribe a su Ley contra las enfermedades infecciosas en el campo de la seguridad o dentro de la "policía administrativa", pero reconociendo que sus poderes ordinarios y extraordinarios están sometidos a los máximos rigores del ordenamiento (infra III). 


\subsection{La distinción entre las declaraciones formales de emergencia (extraordinaria) y su efectivo ejercicio fuera de tales declaraciones}

Más allá de la pugna por las sucesivas "coberturas formales» para restringir derechos fundamentales (alarmas, entre-alarmas, postalarma, legislación sanitaria, excepción), lo cierto es que, en mayor o menor medida, se han ejercido sin solución de continuidad poderes extraordinarios que, como se ha dicho, no se han limitado a las restricciones generales de los derechos fundamentales, sino que además han podido alcanzar a otros pilares del Estado, como el sistema de fuentes. Así ha ocurrido también cuando cesaban los estados de alarma con tantos reglamentos sanitarios, aprobados, además, sin habilitación formal ni regulación legal suficiente ${ }^{29}$.

\section{UN RESUMEN SOBRE LA DISTINCIÓN ENTRE EL DERECHO ORDINARIO Y EL EXTRAORDINARIO}

En términos muy simples y a nuestro limitado propósito: en el Derecho ordinario, los actos jurídicos del Ejecutivo — reglamento y acto administrativo- son «aplicativos», siguen la cascada reguladora habitual: una ley que delimita y prevé con la exigible precisión presupuesto de hecho y consecuencia jurídica, un reglamento que ejecuta o implementa en su caso la ley, y un acto de aplicación. Por definición, el reglamento no puede crear lo que la ley no ha autorizado en materias reservadas a la ley, sino solo ejecutar - concretarla ley previa, menos aún contradecir y desplazar a las leyes ${ }^{30}$. En el Derecho extraordinario, por el contrario, el reglamento —el gran protagonista- puede ser "creativo» e innovador, hasta el punto de oponerse a las leyes en los supuestos establecidos ${ }^{31}$.

29 Infra IV. Pareciera como si el hecho de cesar el estado de alarma hubiera traído consigo de facto el cese del derecho extraordinario, como si desde ese momento ya no se hubieren ejercido poderes de emergencia, y todo ello pese a lo que evidenciaban los diarios oficiales. A la alarma, pues, no le ha seguido la normalidad, sino la excepcionalidad. No ha habido antinomia, ni dualismo «alarma-normalidad», aun cuando no siempre se hayan limitado, ni en la misma medida, todos los derechos.

30 Ciertamente, la distinción no es geométrica ni perfecta, puesto que la previsión normativa no puede ser exhaustiva. De ahí que tenga sentido la autorización o ratificación clásicas de las medidas singulares.

31 A título de ejemplo, infra III. De cuanto antecede, se aprecia fácilmente que tantos reglamentos dictados al amparo del art. 3 Ley 3/1986 por las comunidades autónomas no cumplen con las indicadas exigencias del derecho ordinario. Y operan como si se incardinaran en la órbita del derecho extraordinario, aunque sin la habilitación del art. 116 CE. 


\section{LA ABDICACIÓN DE LA «FUNCIÓN LEGISLATIVA DEL ESTADO» (ART. 66.2 CE)}

\section{LAS DIVERSAS OPCIONES DEL LEGISLADOR ESTATAL}

Sin perjuicio de cuanto luego se diráa ${ }^{32}$, cabe anticipar a la vista del epígrafe anterior que la legislación sanitaria vigente no da cobertura suficiente, salvo para pocas cosas de ordinaria administración en la lucha contra la COVID-19, y que, en consecuencia, no satisface los requerimientos más elementales del principio de legalidad y de la reserva de ley ${ }^{33}$, por distintos conceptos ${ }^{34}$.

Queda fuera de nuestro objeto el estudio - en positivo- de las alternativas y combinaciones legislativas posibles. Pero las hay ${ }^{35}$. Lo que importa ahora es notar, primero, que la legislación sanitaria vigente no es una ley de lucha contra las enfermedades infecciosas ${ }^{36} ; \mathrm{y}$, segundo, que sumados los pocos preceptos aislados de las leyes de cabecera ${ }^{37}$ ni siquiera constituyen un entramado que dé soporte completo al ejercicio de las potestades ordinarias ${ }^{38}$, menos aún para otorgar «plenos poderes» ${ }^{39}$. Las Cortes Generales podían, y debían, legislar ${ }^{40}$. Sin entrar a

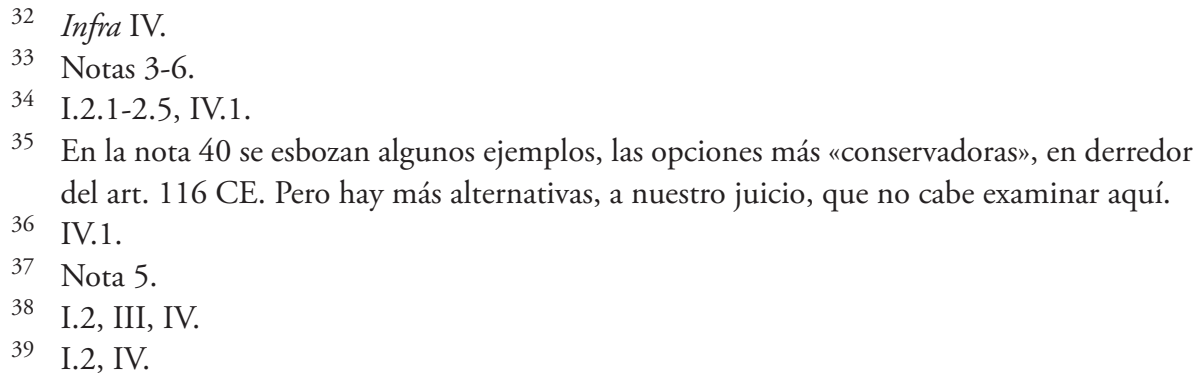

35 En la nota 40 se esbozan algunos ejemplos, las opciones más «conservadoras», en derredor del art. 116 CE. Pero hay más alternativas, a nuestro juicio, que no cabe examinar aquí.

36 IV.1.

37 Nota 5 .

38 I.2, III, IV.

39 I.2, IV.

$40 \mathrm{Y}$ ello en primer término y sobre todo fuera de la cobertura del estado de alarma (I.1.2, IV.1): regulación de las potestades, procedimientos, organizaciones y medidas ordinarias contra la enfermedad infecciosa. Esto es, una ley general contra las enfermedades.

En paralelo, aunque en un plano distinto, cabría haber actualizado la Ley Orgánica 4/1981, de 1 de junio, de los estados de alarma, excepción y sitio (LOAES) dentro del esquema del art. $116 \mathrm{CE}$. Los ejemplos sobre eventuales mejoras de la LOAES a la vista de la experiencia podrían multiplicarse en los tres planos indicados: a) sistema de fuentes (qué, cómo y quién aprueba los reglamentos de emergencia sanitaria, su vigencia temporal y control; exclusión del decreto-ley de la cadena normativa porque constituye un instrumento especial pero del derecho ordinario y cuyas normas además permanecen, etc.); b) derechos fundamentales: cuándo, y en qué condiciones, caben qué tipo de restricciones en el ámbito sanitario sobre qué derechos fundamentales (véase el modelo comparado: III); y c) alteraciones competenciales temporales (ahora previstas de un modo muy insuficiente). Desde luego también habría cabido, sin reforma de la LOAES, aprobar una ley específica contra la COVID-19 (vinculada al art. $116 \mathrm{CE}$ para el ejercicio de potestades extraordinarias), comprensiva de las cuestiones principales, y modificadora en su caso de preceptos concretos de otras muchas leyes mientras dure la pandemia, como han hecho Reino Unido, 
valorar ahora las diversas fórmulas de cumplimiento del deber de legislar ${ }^{41}$, lo cierto es que la aprobación de una ley contra las infecciones o enfermedades contagiosas resulta constitucionalmente exigible ${ }^{42}$, bien sea para el ejercicio de potestades ordinarias, bien sea para el de potestades extraordinarias (donde la legalidad formal reforzada ha de combinarse con la intervención del Parlamento mediante la declaración que corresponda).

\section{EL PROBLEMA CONSTITUCIONAL DE FONDO}

Conviene deslindar el tema constitucional de origen, que no es otro que la inactividad de las Cortes Generales ${ }^{43}$ para regular el ejercicio de poderes ordinarios y, ante todo, extraordinarios (y tantas cuestiones conexas), de los problemas derivados por consecuencia o conexión. La omisión adquiere una mayor trascendencia constitucional, desde luego, cuando la excepcionalidad se mantiene fuera del estado de emergencia del art. 116 CE. Porque, en tal caso, de esa omisión se desprenden además otros problemas constitucionales, al forzar a las comunidades

Francia o Alemania: desde la celebración de las elecciones y las cuestiones competenciales, pasando por la participación y organización de los expertos, hasta las ayudas económicas y sociales. Infra III. Respecto de Francia, véase Estelle Chambas, Thomas Perroud, «France: Legal Response to Covid-19», en OxConLaw, julio de 2021).

41 Véanse II.4 y IV. Así, por ejemplo, queda fuera de nuestro examen el carácter de una ley general contra la COVID-19 (nota anterior), y que por hipótesis podría contener preceptos de naturaleza orgánica, básica y ordinaria, según los casos. Desde luego, todo lo que guarde relación con los poderes de emergencia extraordinaria — que es la clave de todo análisisha de tener naturaleza orgánica, puesto que no es sino un desarrollo o especificación del art. $116 \mathrm{CE}$.

Pero es que ,además, si se trata de medidas sanitarias en el ámbito del derecho ordinario, habría de concluir en igual sentido: no les sería tampoco de aplicación, a nuestro juicio, la doctrina de la reserva de ley orgánica relativa a los "límites» de los derechos, lo que, traducido al lenguaje jurídico-administrativo, equivale a hablar del «régimen legal» del sector de que se trate. Con las restricciones — generales y singulares - para luchar contra enfermedades contagiosas no se define desde luego el régimen ordinario del derecho en cuestión; se hace algo muy distinto, se actúa de modo excepcional, con los riesgos que ello comporta.

Baste un ejemplo, aunque referido a un derecho de la sección segunda: el régimen de los horarios comerciales no es más que una pieza del régimen jurídico del comercio, y no un desarrollo de las facultades de iniciar y sostener la actividad empresarial de que se trate, en que consiste la libertad de empresa (art. 38 CE, STC 83/1984). Sin embargo, las restricciones que se producen en el ámbito del derecho extraordinario no han de ser vistas desde ese ángulo, pues a su través no se establece el régimen jurídico ordinario de un sector, sino algo muy distinto.

42 Notas 4-6. I.2, IV.1.

43 I.2, II.1, III y IV. Por lo demás, a estos efectos, no se consideran las conversiones en ley de los decretos leyes, puesto que con ellas no se ha realizado una regulación tal. 
autónomas y a los jueces a llevar a cabo actividades contrarias a la Constitución: a hacer uso de potestades ordinarias y extraordinarias sin habilitación formal ni directriz legislativa ${ }^{44} \mathrm{y}$ a desplegar funciones cuasi normativas, respectivamente ${ }^{45}$.

\subsection{La resistencia de las Cortes a aprobar un derecho extraordinario de emergen- cia sanitaria}

La posición oficial en este caso podría resumirse así: la alarma mantenida a lo largo del tiempo (sin necesidad de ir acompañada de una ley contra las enfermedades infecciosas) y, en su defecto, la legislación sanitaria existente ofrecerían cobertura suficiente para adoptar todas las medidas necesarias.

Dejando al margen ahora los argumentos jurídicos que de contrario cabe esgrimir ${ }^{46}$, lo cierto es que Gobierno y Cortes Generales no parecen convencidos de esa tesis cuando a la omisión del deber de legislar se le une una actitud positiva y beligerante ${ }^{47}$, obligando, primero, a las comunidades autónomas a aplicar un estado de alarma progresivamente rebajado y una legislación sanitaria que no puede otorgar poderes excepcionales ni contiene garantías equivalentes, $y$, segundo, a los jueces a compartir funciones cuasi normativas. Si el marco legislativo fuera realmente bastante, no hubieran sido necesarias esas artificiosas operaciones de «alejamiento» de la respuesta legal a la COVID-19 desde el centro —las Cortes Generales - hacia la "periferia»; desde el poder legislativo hacia el Ejecutivo autonómico y hacia el poder judicial. Los parlamentos centrales de Reino Unido y Alemania, por ejemplo, han asumido su responsabilidad, sin perjuicio de conferir o regular las competencias que a los demás niveles de gobierno correspondan (III).

44 Para ilustrarlo, infra III y IV.1.

45 II.1.2.c), IV.2. No cabe detenerse aquí. Baste notar que la inconstitucionalidad de esta función cuasi normativa no deriva del hecho de que se establezca un control judicial previo (lo cual sería perfectamente admisible), sino de su objeto. En efecto, se trata de algo más que de un "control» abstracto de normas basado en sustancia en la proporcionalidad en la ley, lo que resulta ya de por sí poco aprehensible en sede judicial (infra IV.2), siendo de esta manera que su apreciación técnica y fáctica corresponde en primer lugar al legislador. Es sobre todo que la ratificación se concibe legalmente - en abstracto- como una "coproducción», más que como un "control» (sin parámetros de contraste), pues se le pide al órgano jurisdiccional que opine sobre una medida política, expresada en un proyecto de norma, que crea o innova el ordenamiento, esto es, que no se limita a aplicar una ley determinada, y de cuyo sentido positivo nace su vigencia misma.

Por lo demás, esta intervención judicial no puede compensar ni suplir la ausencia de habilitación y de regulación legal (nota 178). Parece una verdadera maniobra de distracción para generar la ilusión de un control judicial.

I.2, III-IV.

47 II.1.2, V. 


\subsection{La externalización del coste político de la lucha contra la pandemia hacia las comunidades autónomas y los jueces}

A tal efecto se han realizado tres operaciones jurídicamente objetables ${ }^{48}$ :

a) De un lado, desde las instancias centrales se ha producido una progresiva degradación en el uso del instrumento de derecho extraordinario disponible (art. $116 \mathrm{CE}$ y LOAES $)^{49}$. El último estado de alarma general $(2020 / 21)^{50}$ ha terminado por incurrir en la deslegalización de los criterios justificativos ${ }^{51}$, en la delegación generalizada ${ }^{52}$ y en la desaparición del Congreso en su control quincenal ${ }^{53}$.

b) De otro, se ha insistido en la suficiencia de una legislación sanitaria pese a la notoria vaciedad del art. 3 Ley 3/1986 y la continuada excepcionalidad de iure y de facto - para dar soporte a la acción de las comunidades autónomas, sin reforma legal alguna ${ }^{54}$.

c) Para cerrar el círculo - y lograr una cierta tolerancia social hacia las restricciones autonómicas, ya no estatales—, se les confiere a los jueces funciones que no les competen, al transformar las técnicas de la autorización y de la ratificación, que operan por definición en relación con las medidas administrativas singulares5, en un control abstracto (y etéreo) de normas ${ }^{56}$. Ante la resistencia de los juzgados a aceptar medidas restrictivas generales sin la cobertura del art. $116 \mathrm{CE}$ y/o ante la

48 Nota 1, núm. I.1 y IV.1.

49 A ello puede no ser ajeno el hecho de la inexistencia de una ley general contra las enfermedades infecciosas (I.1.2, III, IV.1). Y es que la alarma parece idónea para afrontar situaciones imprevistas y acotadas en el tiempo y en el espacio, esto es, para enfrentar la incertidumbre y gobernar lo imprevisible, pero no para mantener a lo largo del tiempo y del espacio una simple cobertura formal para la acción gubernamental, sin ir acompañada de normas sustantivas, procedimentales y organizativas, de todo un programa legislativo. El hecho es que en marzo de 2020, numerosos países de referencia (EE.UU., Alemania, Reino Unido, Francia...) aprobaron en sus parlamentos las leyes necesarias, porque se sabía qué medidas típicas convenía adoptar, por más que se le reconozca al Ejecutivo un amplio margen de maniobra.

Así, el declarado por el Real Decreto 926/2020, de 25 de octubre https://bit.ly/3oWDQjR.

51 Ibíd. art. 9.1.

52 Ibíd. art. 2.

53 Ibíd. art. 14; Resolución de 29 de octubre de 2020, del Congreso de los Diputados https:// bit.ly/317SLqi. Del ordenamiento se deriva, sin embargo, una conclusión contraria (Art. 116 CE, 162 del Reglamento del Congreso de los Diputados), si se tiene en cuenta además el concepto jurídico de prórroga (nunca superior al plazo principal) y el principio democrático que obliga a compensar ex post el déficit democrático que suponen los poderes extraordinarios atribuidos al Gobierno.

54 Hasta el punto de que el Gobierno ha recurrido cualquier intento del legislador autonómico para dotar de cobertura y regulación legal a sus respectivas autoridades sanitarias. Así, el recurso de inconstitucionalidad del Gobierno contra la Ley de la Comunidad Autónoma de Galicia 8/2021, de Salud (BOE, 102, de 29 de abril de 2021).

55 Igualmente apreciables en el derecho comparado. Véase III.1.

IV.2. 
natural diversidad de sus resoluciones, consecuencia a su vez de la variedad de circunstancias sometidas a su conocimiento, el legislador responderá encomendando esa función a los TSJ, afirmando por la puerta de atrás —a través de una reforma procesal y sin previa ley sustantiva — que las comunidades autónomas estarían habilitadas para establecer restricciones generales de los derechos fundamentales ${ }^{57}$. Y ante la inevitable diversidad de respuestas de los TSJ y/o la oposición de estos a participar en una función cuasi normativa ${ }^{58}$, el Gobierno responderá mediante decreto ley creando un nuevo recurso de "casación» ante el $\mathrm{TS}^{59}$.

El legislador, pues, ha presionado al poder judicial haciéndolo corresponsable — ante la sociedad - con las comunidades autónomas, de la respuesta jurídica a la COVID-19. Como si el problema fuera de los jueces y tribunales, y no del legislador estatal.

\section{PROBLEMAS CONSTITUCIONALES DERIVADOS EN PERÍODOS DE «ENTRE ALARMAS» Y DE «POSTALARMA»}

De un lado, el ejercicio de poderes extraordinarios - y aun de ordinarios - sin base jurídica (habilitación y regulación) supone una «materialización difusa y sistémica» de vulneraciones constitucionales a manos de comunidades y ciudades autónomas (de la reserva de ley, del principio de legalidad, del sistema de fuentes del derecho, de la vinculación a los derechos fundamentales... y de la democracia parlamentaria). De otro, la aceptación en sede jurisdiccional de normas administrativas sin base jurídica suficiente o un sistema de fuentes desarbolado (en lugar de rechazar - entre otras cosas - que un reglamento pueda desplazar a las leyes ${ }^{60}$ ), y la colaboración en el mecanismo de «ratificación» de normas, en vez de oponerse mediante cuestión de inconstitucio-

57 Art. 10.8 de la Ley 29/1998, reguladora de la jurisdicción contencioso-administrativa, introducida por la disposición final 2.2 de la Ley 3/2020, que pretende transformar el control judicial en cogobernanza al prever que los jueces autoricen o ratifiquen las medidas generales restrictivas de derechos fundamentales, presumiendo además que el minúsculo art. 3 de la Ley Orgánica 3/1986 le estaría otorgando esos poderes a los Ejecutivos autonómicos, poderes que incluirían — aunque no se advierta— la potestad de desplazar a las leyes mediante los reglamentos sanitarios.

Por lo demás, e irónicamente, las Cortes Generales no dudan, esta vez sí, en acudir a ley parlamentaria para externalizar la responsabilidad política hacia comunidades autónomas y jueces.

58 Cuestión de inconstitucionalidad 62832020 planteada por el TSJ Aragón en relación con el art. 10.8 LJCA.

59 Art. 15.3 del Real Decreto Ley 8/2021, de 4 de mayo. Infra IV.2.

$60 \mathrm{Y}$ ello con independencia de que las leyes pretendidamente inaplicables a manos de un reglamento se refieran al ejercicio de derechos fundamentales o de cualquier otra libertad de configuración legal. 
nalidad, supone asumir el desbordamiento del principio democrático y de la división de poderes.

\section{4. ¿ंREMEDIOS JURÍDICOS DIRECTOS FRENTE A LA INACTIVIDAD PARLAMENTARIA? LA EXPERIENCIA COMPARADA}

Pocos remedios jurídicos cabe esperar que ponga a disposición un Parlamento que se niega a ejercer su función constitucional más genuina — de legislar y de controlar al Gobierno- en contra de las esencias de la democracia parlamentaria.

No obstante, la comunidad jurídica ha de explorar todas las opciones posibles para proponer soluciones. Una de ellas la proporciona el modelo alemán, que admite el recurso de amparo ante la inactividad del legislador parlamentario, en la medida en que ello pueda implicar la desprotección de los derechos fundamentales.

Se trata de un recurso de amparo por omisión que se dirige directamente contra el Parlamento ${ }^{61}$. El demandante deberá invocar un mandato de la Constitución del que se derive con claridad el deber de legislar ${ }^{62}$. En el caso de la protección contra la infección, el recurso se habría de fundar en primer término en el deber de proteger la vida y la salud que pesa sobre el legislador ${ }^{63}$, aun cuando puedan invocarse otros derechos fundamentales, si concurre una incompleta inactividad legislativa en relación con las enfermedades infecciosas en general y con el coronavirus en particular.

Procesalmente, allí se distingue entre el amparo deducido frente a una completa inactividad (cuyo enjuiciamiento resulta más simple) de aquellos otros supuestos en los que la legislación deviene insuficiente, en cuyo caso la impugnación se basará, no en la pura omisión, sino en la insuficiencia de la protección del derecho fundamental de que se trate ${ }^{64}$. Con todo, en este último caso el control

61 Sentencia de 30 de junio de 2015 (BVerfGE 139, 321, 346, párr. 82); Sentencia de 24 de marzo de 2021 (1 BvR 2656/18 -, Rn. 1-270, párr. 95). Quiero expresar mi agradecimiento al profesor Martin Eifert, de la Universidad Humboldt de Berlín, por la información y orientación facilitada en esta materia.

62 Ibid. primera sentencia citada.

63 Nuestro art. 15 CE, a diferencia del art. 2.II GG, no invoca a la ley. No obstante, la vinculación del Parlamento a los derechos fundamentales (art. 9.1, 53.1 CE), y las expresivas llamadas a la ley no ya solo del 53.1 CE, sino del entero título I, y de otros muchos preceptos (art. 103.1) permiten construir, según los casos y los derechos implicados, un deber positivo de legislar.

Téngase en cuenta que la STC 181/2000, FJ 8, puede constituir un primer paso en esa dirección. Agradezco a la profesora Margarita Beladiez Rojo la observación respecto de la referida sentencia constitucional, así como las conversaciones mantenidas sobre otros aspectos constitucionales relacionados con este trabajo, que sin duda han contribuido a enriquecerlo.

64 Sentencia de 24 de marzo de 2021, cit. párr. 95. 
de suficiencia por parte del Tribunal Constitucional ha de ser limitado ${ }^{65}$. Para que se entienda satisfecho el deber de legislar, el Tribunal Constitucional exige que el Parlamento intervenga mediante un proceso legislativo formal, sin que baste una mera participación parlamentaria ${ }^{66}$.

\section{UNA MIRADA COMPARADA SOBRE EL PRINCIPIO DE LEGALIDAD EN LA LUCHA CONTRA LA COVID-19}

A los efectos, primero, de ilustrar la obligada acción del parlamento cuando irrumpe la COVID-19 aun cuando se contara en marzo de 2020 con una moderna y completa infraestructura legal (lo que no era nuestro caso) y, segundo, de inducir el sentido y contenido de las potestades de emergencia extraordinaria en contraste con los poderes ordinarios en la lucha contra enfermedades contagiosas, se ofrece una apretada síntesis de dos países de referencia.

\section{REINO UNIDO}

1.1. Introducción. La infraestructura legal previa a la pandemia de la COVID-19: la Ley de Salud Pública para el Control de Enfermedades (1984) y la Ley de Emergencias Civiles (2004)67

Antes de la COVID-19, el Reino Unido disponía de dos leyes para luchar contra las enfermedades contagiosas, en la que se regulaban en detalle los poderes ordinarios y extraordinarios que podía ejercer el Ejecutivo en cada caso.

65 Ibid., párr. 152. La explicación es evidente: «Los derechos subjetivos de defensa contra la injerencia del Estado que se derivan de los derechos fundamentales, por un lado, y los deberes de protección que se derivan del significado objetivo de los derechos fundamentales, por otro, difieren fundamentalmente entre sí en que el derecho de defensa prohíbe una conducta estatal concreta en su objetivo y contenido, mientras que el deber de protección es fundamentalmente indeterminado».

La jurisprudencia concluye, pues, en la violación del deber de legislar cuando no se aprueba ley alguna, cuando esta resulta manifiestamente insuficiente o inadecuada para satisfacer el fin perseguido, o se queda muy por debajo del nivel de protección (ibid.).

66 Ibid. (véase el resumen de la sentencia, núm. 5). Lo que, en nuestro caso, debiera excluir la convalidación del decreto ley, de lectura única y votación a la totalidad en una sola cámara, con frecuentes contenidos heterogéneos y en todo caso ajenos en rigor a los derechos fundamentales; así como la resolución por la que se prorroga el estado de alarma.

67 La elaboración de esta síntesis se basa en el estudio de la legislación, con el apoyo de la bibliografía que se cita seguidamente, y en primer lugar el estudio de Jeff King y Natalie Byrom, "United Kingdom: Legal Response to Covid-19», en OxConLaw, 2021. Quiero expresar mi agradecimiento al profesor Jeff King por su paciente, generosa y concienzuda dedicación para resolver las dudas que el análisis del sistema británico me ha planteado a fin de obtener un retrato fiable a los efectos del presente artículo. 
a) La primera es la Ley de Salud Pública (de Control de Enfermedades) de $1984^{68}$. En su versión original aludía a infecciones tales como el cólera, la viruela o el tifus, entre otras ${ }^{69}$, alineándose en esencia con lo que hemos denominado aquí «emergencia ordinaria»"

Con el paso del tiempo y las sucesivas reformas ${ }^{71}$, sin embargo, se había transformado en una ley mucho más ambiciosa y completa en la lucha contra las epidemias. Se trata de una ley que distingue de forma sistemática y ordenada entre las restricciones de carácter singular de los derechos y libertades, con un evidente protagonismo judicial ${ }^{72}$, y las restricciones generales a través de reglamentos sanitarios de emergencia, sometidos a su vez a procedimientos específicos de control y aprobación parlamentarios e importantes requisitos legales ${ }^{73}$. En un

68 Public Health (Control of Diseases) Act 1984. Es una legislación originariamente aprobada para Inglaterra y Gales. La versión original, que puede verse en https://bit.ly/3COmNFv (visitada en julio 2021), tuvo un planteamiento mucho más modesto. Fue reformada profundamente en 2008 por la Health and Social Care Act 2008, que le confirió la sistemática actual, aun cuando ha experimentado otras reformas más puntuales hasta la actualidad. De acuerdo con su texto introductorio, la ley tiene por objeto consolidar ciertas leyes relacionadas con el control de enfermedades y con el establecimiento y las funciones de las autoridades sanitarias portuarias, incluidas las leyes relativas al entierro y la cremación y con la regulación de los alojamientos comunes y los barcos de canal.

69 Art. 10 (versión original). Supra I.2.2.

70 De un lado, muchas de las medidas restrictivas tenían carácter singular o individual. De otro, el art. 13, que autorizaba a dictar reglamentos ejecutivos para el control de enfermedades, preveía restricciones hasta cierto punto de escasa relevancia sobre derechos fundamentales, con vistas al tratamiento de las personas afectadas por cualquier enfermedad epidémica, endémica o infecciosa y para prevenir la propagación de dichas enfermedades, o para prevenir el peligro para la salud pública de los buques o aeronaves que lleguen a cualquier lugar, y para prevenir la propagación de la infección por medio de cualquier buque o aeronave que salga de cualquier lugar.

Por lo demás, las potestades de reglamentación previstas en la Ley de 1984 no pueden utilizarse, por ejemplo, para obligar a una persona a someterse a un examen médico; a ser trasladada a un hospital o a un establecimiento similar; o a ser internada en él; o, lo que es más importante, a ser mantenida en aislamiento o cuarentena. Estas medidas altamente invasivas deben adoptarse caso por caso (es decir, persona o grupo) y no a escala comunitaria. Véase Jeff King, Natalie Byrom cit. en nota 67 núm. 97.

71 La ley fue objeto de una profunda reforma en 2008 (nota 68), con ocasión de la transposición al ordenamiento interno de los reglamentos internacionales de la OMS — tras la pandemia de SARS- Ha experimentado otras reformas más puntuales, también en 2020 .

72 La lectura de los preceptos reguladores de las medidas (45G-45M) evidencia ya la distancia con nuestra pobre Ley 3/1986, en términos de legalidad, certidumbre, reserva de ley, garantías y controles.

73 Arts. 45B-45F. 
caso y en otro solo se pueden aplicar las medidas restrictivas que expresamente permite la ley ${ }^{74}$.

- Las medidas sanitarias de carácter singular o individual ${ }^{75}$ se clasifican por su afección a las personas ${ }^{76}$, a las $\operatorname{cosas}^{77}$, o a las instalaciones ${ }^{78}$. La Ley determina el procedimiento para su adopción, la duración de estas y su control ${ }^{79}$

- Las medidas sanitarias de alcance general, adoptadas mediante reglamento $^{80}$, pueden igualmente ir referidas a personas, cosas e instalaciones ${ }^{81}$ en determinados ámbitos. Así, a los ministros competentes que señala la Ley se les atribuye la potestad de aprobar reglamentos con el fin de evitar la propagación de enfermedades infecciosas y, en particular, se les permite elaborar reglamentos sanitarios sobre viajes "para dar efecto a cualquier acuerdo o convenio internacional relativo a la propagación de la infección o la contaminación ${ }^{82}$; así como acordar ciertas restricciones cuyas materias enumera ${ }^{83}$. No se trata de una potestad reglamentaria genérica, sino

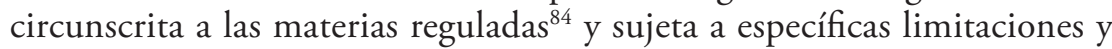

74 Se establece, en suma, un régimen jurídico diferenciado y propio para cada una de estas dos vías. En el primer caso, la autorización de las medidas singulares se confía a los jueces, mientras que en el segundo el control político de los reglamentos sanitarios se le atribuye al Parlamento.

75 Son órdenes impuestas por el juez de paz en colaboración con la autoridad sanitaria (art. 45G-45M).

76 Art. 45G. El juez (véase nota anterior) puede acordar el examen médico, el ingreso hospitalario, la obligación de llevar protección, etc.

77 Art. 45H. Si una cosa puede estar infectada o contaminada, el juez (véase nota anterior) puede acordar su aislamiento o cuarentena, por ejemplo.

78 Art. 45I. Análogo al ejemplo de nota anterior, aunque referido a una instalación.

79 Arts. 45G-45O.

80 Ha de recordarse que los reglamentos en el Reino Unido tienen la consideración de «legislación delegada». De ahí el tradicional control parlamentario. Dentro de ese contexto, los reglamentos de emergencia sanitaria están sometidos a controles específicos. Con carácter general, véase Jeff King (2020), «The Province of Delegated Legislation», en The Foundations and Future of Public Law: Essays in Honour of Paul Craig, OUP. Para una perspectiva comparada de la posición del reglamento y su control —en tiempos ordinarios—, véase Susan Rose-Ackerman (2021), Democracy and Executive Power: Policymaking Accountability in the US, the UK, Germany and France, Yale University Press.

81 Art. $45 \mathrm{C}(3)$.

82 Art. 45B

83 Art. 45C. Cierre de las escuelas, prohibición o restricción relativa a la celebración de un evento o reunión, restricción o condiciones relativas a la manipulación, transporte, inhumación o incineración de cadáveres o de restos humanos.

Ibid. 
prohibiciones ${ }^{85}$. Asimismo, la Ley estipula un conjunto de criterios escalonados para garantizar que la proporcionalidad presida la elaboración de los reglamentos de salud pública ${ }^{86}$.

Aunque la Ley de 1984 no impuso una vigencia temporal para los reglamentos aprobados a su amparo - como hacen las Leyes de Emergencias Civiles de 2004 y del Coronavirus de 2020, a las que seguidamente se alude—, en la práctica, sin embargo, los mismos reglamentos así lo han dispuesto con frecuencia ${ }^{87}$.

La Ley de 1984, en su configuración actual, se sitúa, pues, en un punto intermedio entre la emergencia ordinaria ( $\mathrm{y}$ ahí se incluyen todas las injerencias individuales acordadas judicialmente) y una (limitada) emergencia extraordinaria (ejercida a través de reglamentos sanitarios especiales) ${ }^{88}$. Las restricciones más gravosas que se han aplicado durante la pandemia han sido adoptadas en virtud de esta Ley ${ }^{89}$.

b) La segunda ley anterior a la COVID-19 es la Ley de Emergencias Civiles

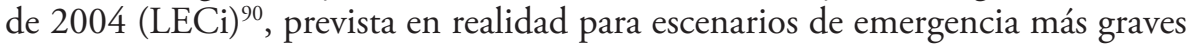
o extraordinarios que los que contempla la Ley de 1984, y entre otros, para hacer frente a acontecimientos o situaciones que amenacen con causar un daño grave al bienestar humano en cualquier lugar porque impliquen, causen o puedan causar

85 Entre otros, art. 45D (restricciones a la potestad reglamentaria del art. 45C) y 45E (prohibición de imponer mediante reglamento tratamiento médico). Por su parte, el art. 45F añade otras medidas complementarias que pueden regular los reglamentos sanitarios, tales como atribuir funciones a las autoridades locales y a otras personas; prever la ejecución y el cumplimiento de las restricciones y los requisitos impuestos por los reglamentos o en virtud de ellos; prever recursos y revisiones de las decisiones adoptadas en virtud de los reglamentos; permitir o exigir el pago de incentivos, compensaciones y gastos; etc. Jeff King, Natalie Byrom cit. en nota 67 núm. 25: 45D(1); 45D(4)(a); 45R(2); 45F(7)(8); todo reglamento aprobado al amparo del art. $45 \mathrm{C}$ ha de prever un recurso, según el $45 \mathrm{~F}(6)$; sobre protecciones adicionales ante las restricciones adicionales $45 \mathrm{C}, 45 \mathrm{D}, 45 \mathrm{~F}$, 45Q; 45E; etc. Los mismos autores afirman, sin embargo, que la urgencia y la proporcionalidad en sí mismas no son materias que resulten fácilmente fiscalizables en sede judicial (núm. 26).

87 Jeff King, Natalie Byrom cit. en nota 67 núm. 26.

88 Así se infiere con naturalidad de la parte $2^{a}$ de la ley y de los preceptos antes citados. Véase asimismo Lord Sumption, "Government by decree», citado en nota 1. Podría decirse que el carácter parcialmente extraordinario deriva del hecho de que estos reglamentos, aunque delimitados de forma positiva y negativa, no son puramente ejecutivos (véase nota 80). Ello ha originado la polémica sobre la falta de cobertura legal que ofrece esta ley para acordar el confinamiento generalizado de personas sanas, puesto que, en efecto, la ley solo habla de confinar a personas sospechosas de estar contagiadas. A juicio de Lord Sumption ello incurre en ultra vires: "Government by decree», nota 1 . 
pérdida de vidas humanas, enfermedades o la interrupción de los servicios relacionados con la salud ${ }^{91}$.

La LECi actualiza los supuestos de emergencia civil grave, incluida la sani$\operatorname{taria}^{92}$. La Ley prescribe que los reglamentos de emergencia sean examinados en el Parlamento en un plazo de siete días a partir de su elaboración (de lo contrario pierden su vigencia) y pueden ser modificados por resolución de ambas cámaras ${ }^{93}$; asimismo dispone en qué forma pueden desplazar a las leyes del Parlamento ${ }^{94}$, la obligación de renovar su vigencia a los treinta días ${ }^{95}$, la prohibición de utilizarlos en determinadas materias y ámbitos ${ }^{96}$, así como su control parlamentario ${ }^{97}$.

A esta Ley subyace el entendimiento de que la legislación secundaria de emergencia (esto es, los reglamentos aprobados en virtud de la LECi) es extremadamente peligrosa en términos constitucionales ${ }^{98}$. De ahí que su ejercicio deba observar tres requisitos legales. En primer lugar, el punto de partida se sitúa en su

91 Art. 1(1), 1(2). El art. 1(1) añade en esa lista cerrada: un acontecimiento o situación que amenace con causar un dańo grave al medio ambiente de un lugar del Reino Unido, o una guerra o terrorismo que amenace con causar un dańo grave a la seguridad del Reino Unido.

92 En el Reino Unido no existe un procedimiento constitucional formalizado para declarar el estado nacional de emergencia, pero esta ley hace las veces de una tal declaración y es su equivalente funcional. Véase Jeff King, Natalie Byrom cit. en nota 67 núm. 11. Al invocar las medidas que la ley contempla, el Gobierno está afirmando que «esto es una emergencia». Como los reglamentos están sujetos a control y participación parlamentarios (hay diversos procedimientos de aprobación), la vigencia del estado de alarma y el ejercicio de los poderes de emergencia no quedan en las manos exclusivas del Ejecutivo. Jeff King, Natalie Byrom cit. en nota 67 núm. 11.

94 Arts. 20 y ss., 26, 27 y 28 . Véase nota 80.

95 Art. 26: los reglamentos nacen con «fecha de caducidad» de treinta a días a contar desde la fecha en que son aprobados, o pierden su vigencia antes si así lo dispusieran.

96 Tienen un ámbito material delimitado, en más (art. 22.3: pueden regular lo que podría regularse mediante ley en el Parlamento en el ejercicio de una prerrogativa real) y, sobre todo, en menos (art. 23.3-5). De entre las materias vedadas a los reglamentos de emergencia cabe destacar las siguientes: no pueden exigir a una persona, o permitir que se le exija, que preste el servicio militar, ni prohibir o permitir la prohibición de participar en una huelga u otra acción industrial, o cualquier actividad relacionada con ella. Las normas de emergencia no pueden entrar en materia penal, ni pueden modificar la parte de la ley que regula los poderes de emergencia (arts. 19-31), ni la legislación de derechos humanos de 1998.

Aunque estas prohibiciones materiales parecen obvias, no son superfluas si se tiene en cuenta, primero, que el reglamento de emergencia puede desplazar a la ley, lo que obliga a fijar qué leyes nunca pueden ser desplazadas por estos reglamentos; y, segundo, porque el Reino Unido carece de Constitución escrita.

Art. 27 y ss.

98 Lord Sumption, «Government by decree», citado en nota 1. 
prohibición: no se podrán aprobar tales reglamentos, salvo que sean necesarios y urgentes; la segunda condición radica en que el derecho ordinario - la legislación existente - resulte insuficiente para resolver el problema; y la tercera, que no haya tiempo de promulgar una ley al respecto, ni siquiera por el procedimiento de urgencia ${ }^{99}$. La LECi se ocupa también de otras materias propias de una situación extraordinaria ${ }^{100}$.

Sin embargo, pese a reconocerse por el propio Gobierno que era la ley apropiada para combatir la pandemia ${ }^{101}$, y tras un intenso debate que aún perdura ${ }^{102}$, no ha sido la elegida, y en su lugar se aprobó una nueva, la Ley del Coronavirus de $2020^{103}$, sobre la base de la Ley de 1984 .

99 Art. 21 (5). De ahí se deriva una conclusión evidente: no toda situación de emergencia legitima sin más la producción de un derecho extraordinario a través de reglamentos, puesto que de entrada cabrá aprobar leyes formales con carácter de urgencia para tiempos de pandemia.

100 Tales como las que se refieren a la organización de los servicios de emergencia y la acción de las autoridades locales, a las responsabilidades de gestión y de información al público, de asesoramiento; a los deberes de cooperación e intercambio de información entre los diversos servicios de emergencia y los servicios públicos y de interés general; y al personal al servicio de la emergencia. Véase parte I, «Disposiciones locales de protección civil». Aspira, en suma, a una planificación y actividad sistémica para enfrentar la emergencia.

101 Jeff King, Natalie Byrom cit. en nota 67 núm. 12

102 La Comisión Constitucional de la Cámara de los Lores ha seguido abierta durante largo tiempo y muchos de los comparecientes han argumentado que debería haberse utilizado la Ley de Emergencias Civiles de 2004, al menos a corto plazo, debido al superior control parlamentario que ofrece. Cfr. Jeff King, Natalie Byrom cit. en nota 67 núm. 12.

Para unos debió aplicarse la LECi de 2004 y para otros la de 1984, aunque incorporando los mecanismos de rendición de cuentas que la de 2004 establecía. Véase el Informe "Covid-19 and the use and scrutiny of emergency powers", de la Comisión Constitucional de la Casa de los Lores (Select Committee on the Constitution: 3rd Report of Session 2021-22), https://bit.ly/3HOTTZu (julio 2021).

103 La razón aducida por la que se prefirió una nueva ley de emergencia sanitaria, la del coronavirus de 2020, en lugar de activar la ley de 2004, estriba en el riesgo de que no diera tiempo de aprobar una legislación nueva — ni siquiera por el procedimiento de urgenciaal amparo de la Ley de Emergencias Civiles de 2004, dados los requisitos tan estrictos que esta establece.

Quiere decirse que con los criterios sentados por la propia ley de 2004 no era «necesario» ese régimen, ya que el Parlamento podía aprobar por vía de urgencia una legislación (primaria, por tanto) aplicable a la situación, en lugar de aprobar reglamentos de emergencia al amparo de aquélla (así se expresa Jeff King respondiendo a mi cuestionario). Lord Sumption, "Government by decree», citado en nota 1 , añade que una explicación plausible para aprobar una ley distinta es también evitar los controles superiores del Parlamento sobre los reglamentos de emergencia que derivan de la LECi. 


\subsection{La Ley del Coronavirus de 2020}

La Ley del Coronavirus de 2020 (LC) ${ }^{104}$, de notable complejidad y extensión ${ }^{105}$, fue aprobada el 25 de marzo de 2020 por vía de urgencia ${ }^{106}$ para hacer frente específicamente a la COVID-19 ${ }^{107}$. Es una ley de emergencia sanitaria (extraordinaria) ${ }^{108}$, de vigencia temporal ${ }^{109}$. Ha formado con la Ley de 1984 el entramado legislativo básico en respuesta a la pandemia.

104 Coronavirus Act 2020.

La ley fue aprobada en un verdadero maratón, con un debate parlamentario necesariamente breve. Ello fue objeto de no pocas críticas.

No obstante, visto desde el continente, una aprobación de urgencia de medidas materiales y sustantivas, organizativas y de procedimiento, de fuentes del derecho, de límites y controles, es preferible a un estado de alarma que obliga al Gobierno a «inventar» cada día qué hacer, con un control parlamentario puntual, o a la aprobación del decreto ley (véase I.1, II, IV.1, V).

105 Es una «ley pesada», de 102 artículos y 29 anexos, en total más de 200 artículos que suman 342 páginas impresas. Véase Jeff King, Natalie Byrom cit. en nota 67 núm. 17.

106 Aunque su primera lectura fue el 19 de marzo de 2020, tuvo tres días de sesión de escrutinio parlamentario (del 23 al 25 de marzo de 2020), solo uno de ellos en la Cámara de los Comunes. El Gobierno afirmó que celebró múltiples conversaciones entre los diversos partidos en la elaboración del proyecto, cosa que fue reconocido por la denominada Oposición Leal durante los debates parlamentarios. Cfr. Jeff King, Natalie Byrom cit. en nota 67 núm. 18.

107 Esta ley complementa la de 1984, pues le atribuye nuevos poderes al Gobierno, al margen de extenderlos también a Escocia.

108 La ley se preocupa en primer término por ampliar los poderes del Gobierno para reunir y organizar todos los recursos médicos disponibles y para autorizar los gastos públicos necesarios. En sus anexos 21 y 22 se esconden, sin embargo, otros dos poderes adicionales para controlar la libre circulación, en relación con las personas infectadas o sospechosas, y respecto de restricciones en reuniones, eventos, cierre de instalaciones, etc. No autoriza, por el contrario, a confinar a personas sanas, siguiendo con ello una larga tradición, en virtud de la cual se podía confinar a las personas infectadas, pero no a las sanas. El confinamiento de personas sanas solo estaba permitido en la ley de 2004, que es la única ley diseńada para emergencias tan graves como para exigir tales medidas. El debate fundamental ha girado en torno a la (falta de) cobertura legal para el confinamiento nacional — por tanto, también de personas no infectadas, ni de personas sospechosas de contagio-. Véase por todos Lord Sumption, "Government by decree» cit. en nota 1. Véase supra I.2.3.

Sin embargo, sí amplía los poderes para la cuarentena de los que hayan dado positivo, así como para realizar pruebas a quienes puedan ser sospechosos de padecer la enfermedad. Véase J. Grogan, «Right Restriction or Restricting Rights? The UK Acts to Address COVID-19», VerfBlog, 2020/4/17, https://bit.ly/3nLiGWu, DOI: 10.17176/20200417182523-0.

109 La parte II (disposiciones finales) distingue entre los preceptos de carácter temporal (la mayoría) y los que no tienen «fecha de caducidad» de dos años (por ejemplo, en materia de personal). 
Añade a la Ley de 1984 una extensa infraestructura legal comprensiva de todas las cuestiones relacionadas específicamente con la COVID-19 ${ }^{110}$ : desde la movilización del personal sanitario y social, o las medidas de contención del virus, hasta el tratamiento de los fallecidos o el apoyo a las personas ${ }^{111}$; desde las elecciones y referendos pendientes ${ }^{112}$, pasando por el uso de la tecnología de vídeo y audio en los procedimientos judiciales ${ }^{113}$, hasta las potestades para cerrar escuelas y guarderías ${ }^{114}$, el cierre de puertos o la restricción de eventos, reuniones o locales ${ }^{115}$. Ello supuso la reforma puntual y temporal de algunas leyes, aunque se trata de modificaciones que solo afectan a la pandemia del coronavirus y que desaparecerán con la ley ${ }^{116}$.

El control parlamentario de los reglamentos aprobados en virtud de la LC resulta más atenuado en ciertos aspectos que en la $\mathrm{LECi}^{117}$. En compensación, durante su misma gestación se aprobaron ciertas garantías adicionales: desde la fecha de caducidad de las previsiones legales de la ley (dos años, aunque con excepciones) ${ }^{118}$ hasta la renovación parlamentaria de los poderes de emergencia cada seis meses ${ }^{119}$.

${ }^{110}$ Jeff King, Natalie Byrom cit. en nota 67 núm. 18.

111 Ibid.

112 Arts. 59-70.

113 Arts. 53-57.

114 Arts. 37, 53-57.

Sehabilitaron nuevos edificios para mantener la seguridad de los que trabajaban y asisten a los tribunales. La participación en los procesos judiciales se consideró una actividad esencial. Se flexibilizaron los plazos. Los tribunales han permanecido abiertos durante toda la pandemia y, desde luego, para impugnar la respuesta del Gobierno a la COVID-19. Véase Jeff King, Natalie Byrom cit. en nota 67 números 48 y ss., 55.

115 Art. 52

116 Se trata, pues, de modificaciones provisionales o no permanentes. Véase Grogan, cit. en nota 108.

117 Y ello porque el control parlamentario permite la aprobación o el rechazo del reglamento, pero no su enmienda. Los reglamentos entran en vigor en el momento de su aprobación, pero han de ser aprobados en el Parlamento dentro de los 28 días siguientes. Es esta una cuestión de más amplio espectro y que excede del control de los reglamentos de emergencia. Véase Jeff King, Natalie Byrom cit. en nota 67 núm. 33, 34. Otra crítica se refiere a que a los ministros competentes se les permite en esta Ley aprobar «directrices» — reglamentos de menor entidad — sin control parlamentario directo. Ibid., núm. 28 y parte IV.A.

118 Art. 89, 90(2).

119 Esta fue la más importante concesión arrancada durante su tramitación parlamentaria: ambas cámaras deben votar afirmativamente una moción que disponga «que las disposiciones temporales de la Ley de Coronavirus de 2020 no expiren todavía» (art. 98). Véase Jeff King, Natalie Byrom cit. en nota 67 núm. 19. 


\section{ALEMANIA}

\subsection{Introducción. La infraestructura legal previa a la pandemia de la COVID-19: la Ley federal contra las enfermedades contagiosas ${ }^{120}$}

Antes de la irrupción de la pandemia, Alemania contaba con la Ley federal de prevención y control de las enfermedades infecciosas en los seres humanos, esto es, con la llamada Ley contra las enfermedades contagiosas, de 20 de julio de $2000^{121}$ (en adelante, LEC), una ley de una notable extensión y detalle ${ }^{122}$, a la que se le encomienda la prevención y la gestión de tales enfermedades ${ }^{123}$. Regula de modo sistemático y con cuidada precisión los poderes ordinarios y extraordinarios que se le confieren al Ejecutivo ${ }^{124}$, así como las medidas que cabe adoptar en prevención de las enfermedades infecciosas.

Esta Ley ha sido modificada puntualmente desde marzo de 2020 en función de las cambiantes circunstancias de la COVID-19 a través de las llamadas leyes de protección de la población (en adelante, LPP) ${ }^{125}$. La primera LPP se aprueba el 27 de marzo de 2020 y en su virtud se exige una previa declaración de estado de emergencia sanitaria de alcance nacional en la Cámara baja (Bundestag) y, mientras ésta dure, se le atribuyen al ministro federal de Sanidad nuevas potestades reglamentarias de emergencia ${ }^{126}$.

${ }^{120}$ La elaboración de esta síntesis se basa en el estudio de la legislación, con el apoyo de la bibliografía que se cita seguidamente, en primer lugar, el estudio de Anna-Bettina Kaiser y Roman Hensel, «Germany: Legal Response to Covid-19«, en OxConLaw. Quiero expresar mi agradecimiento a Roman Hensel, profesor ayudante del Departamento de Derecho Público y Fundamentos del Derecho de la Universidad Humboldt de Berlín, por su amable y concienzuda orientación a fin de asegurar la fiabilidad de la presente exposición a nuestro limitado propósito.

121 Gesetz zur Verhütung und Bekämpfung von Infektionskrankheiten beim Menschen. También conocida como Ley de protección contra las infecciones. Entró en vigor el 1 de enero de 2001.

12277 artículos y cerca de 80 páginas impresas.

123 Anna-Bettina Kaiser y Roman Hensel, cit. en nota 120 núm. 14.

${ }^{124}$ En este caso, con la intervención expresa del Parlamento: véanse las tres notas siguientes.

125 Hasta la fecha (julio de 2021) se han aprobado cuatro LPP, la última con fecha de 22 de abril de 2021. Cada una de ellas introduce reformas puntuales en la ley de cabecera, esto es, en la LEC, y en otras leyes, por razón de la COVID-19. Las LPP establecen cláusulas de caducidad de las reformas que introducen en la medida en que entrañan un derecho extraordinario. Las potestades reglamentarias extraordinarias atribuidas al ministro de Sanidad mediante la aprobación del art. 5 han experimentado sucesivas reformas en más y en menos, en función de las circunstancias (se han extendido mediante nueva ley que deroga su fecha de caducidad, y puede renovarse, con la declaración de estado de epidemia del Bundestag cada tres meses; y se han derogado después algunos puntos del art. 5.2).

126 Anna-Bettina Kaiser y Roman Hensel cit. en nota 120 núm. 16 (véase el extenso art. 5 y la nota anterior). 
El modelo alemán, pues, combina, de un lado, la existencia de esta completa Ley general contra las enfermedades infecciosas - sucesiva y puntualmente reformada desde marzo de 2020 - con la activación parlamentaria de las potestades extraordinarias que se le asignan temporalmente al Ejecutivo, de otro, mediante la citada declaración de emergencia ${ }^{127}$.

\subsection{Potestades ordinarias y extraordinarias en la LEC}

a) En la LEC son distinguibles las medidas singulares y las generales. Unos artículos, señaladamente los 28-31, prevén las típicas restricciones de carácter individual que cabe adoptar, sea mediante acto administrativo singular o gene$\mathrm{ral}^{128}$, y otros, como el art. $5^{129}$ o el $32^{130}$, habilitan para aprobar reglamentos sanitarios. La LEC no rebaja sus exigencias desde la perspectiva del principio de legalidad y de la reserva de ley en relación con las medidas singulares - que aparecen densamente reguladas-, ni se limita a habilitar la injerencia respecto de cada uno de los derechos fundamentales afectados, sino que delimita con claridad el presupuesto de hecho y las consecuencias jurídicas en cada caso anudadas ${ }^{131}$. Las injerencias individuales han de ser entendidas como ejercicio de potestades ordinarias.

127 Ibid., núm. 8-9: el estado de emergencia no puede ser declarado formalmente a nivel constitucional, y los derechos fundamentales no pueden ser suspendidos ni siquiera en tiempos de pandemia. La Constitución quiere estar por encima. Y ello porque el estado de emergencia constitucional jugó un papel decisivo en la destrucción de la República de Weimar.

128 Se centran en las personas contagiadas o sospechosas de estarlo (art. 28), y permiten medidas como el confinamiento individual, el sometimiento a observación (art. 29), la cuarentena (art. 30) o la prohibición total o parcial de ejercer actividad profesional (art. 31). En cada caso, y de modo diferenciado, se concretan qué derechos pueden ser limitados. Mientras el art. 28 sirve de entrada a las medidas de protección, los arts. 29-31 lo especifican. Los actos administrativos a su vez no hacen sino concretar y aplicar sus determinaciones. Estos preceptos, en particular el 28 y el 32, han sido modificados puntualmente a través de las citadas leyes LPP (nota 125).

129 Véase la nota 125.

${ }^{130}$ Este precepto ya establecía antes de la pandemia una potestad reglamentaria ordinaria en favor de los Länder (al que la ulterior reforma del art. 28.a.5 para tiempos de pandemia le ha ańadido ciertos requisitos adicionales), en la medida en que se trataba de reglamentos «normales» (esto es, ejecutivos), limitados a aplicar los preceptos legales a los que se ciñe (28-31), de ordinario ideados para personas enfermas o sospechosas de contagio. Véase I.2.3.

131 Nota 128. Las medidas singulares de restricción de derechos fundamentales, pues, como sucede con el modelo británico, no quedan abandonadas a una cláusula general simplemente habilitadora. 
b) La potestad reglamentaria se halla sujeta a una compleja regulación en la LEC. De un lado, cabría hablar de una potestad ordinaria de los Länder para aprobar reglamentos (ejecutivos) en las mismas materias y derechos a que se refieren los citados arts. 28-31 LEC $^{132}$ y observando sus presupuestos y límites ${ }^{133}$, es decir, se trata de normas de carácter general y cuyo objeto es la aplicación o implementación de esos preceptos legales ${ }^{134}$. De otro, es posible identificar potestades reglamentarias extraordinarias otorgadas durante la pandemia y mientras dure la declaración de emergencia, bien (limitadamente) a los Länder ${ }^{135}$, o bien al ministro federal de Sanidad ${ }^{136}$, y que se pueden extender con carácter preventivo a las personas sanas. Estas potestades extraordinarias han sido objeto de enorme atención, repetidas reformas y controles ${ }^{137}$ y no se otorgan de modo genérico o indiferenciado, sino que se matizan en función de la materia ${ }^{138}$, del derecho afectado $^{139}$, de las circunstancias ${ }^{140}$ o de las competencias ${ }^{141}$.

c) Por lo demás, la atenta protección de los derechos fundamentales se deja sentir a lo largo de toda la LEC, y no solo con ocasión de la adopción de medidas singulares o generales, de potestades ordinarias o extraordinarias. Baste destacar que, mientras se mantenga la declaración de emergencia, se ha de respetar la diferenciación y gradación en las restricciones de los derechos fundamentales a los efectos de la LEC, de modo que, por ejemplo, en las condiciones estableci-

132 Nota 130.

133 Art. 32 en su versión anterior a la primera LPP de 27 de marzo de 2020. Véase nota 130.

134 Preceptos que no se limitan a habilitar las injerencias, sino que contienen una cuidada regulación, como se ha notado. Véanse por otra parte las notas 130 y 133 . De hecho, antes de la pandemia no se prestaba especial atención a la habilitación que contiene el art. 28.1 (que permite adoptar "las medidas necesarias de protección", aunque insertas en un contexto y entramado definido). Se trataba de una habilitación centrada en las personas infectadas o sospechosas de estarlo. Puede decirse, como opina Roman Hensel, que durante la pandemia el Ejecutivo ha «descubierto» la posibilidad de proyectar esas medidas a personas sanas.

135 Arts. 28.a y 32. En su virtud pueden incidir también sobre las 17 materias que enumera (que no constituyen, sin embargo, un numerus clausus) y que resultan aplicables a las personas sanas (1). Están sujetos a una vigencia temporal de 4 semanas y a la obligación de motivar su necesidad (5). Anna-Bettina Kaiser y Roman Hensel, cit. en nota 120 núm. 20. No se pueden separar de las leyes, como sucede con la potestad del Ministerio Federal (nota 125). En la práctica se ha hecho un mayor uso de esta potestad, que de la del ministro federal.

136 Nota 125.

137 Anna-Bettina Kaiser y Roman Hensel, cit. en nota 120 núm. 25-32, 45-46.

138 Art. 5, 32

139 Arts. 28-31.

${ }^{140}$ P. ej., reglas especiales para personas vacunadas.

141 P. ej., en casos especiales el reglamento federal puede adoptar medidas de protección uniformes para todo el país (art. 28.b). 
das, las relativas al derecho de reunión, de asamblea (por motivos ideológicos o religiosos) y las que afectan a la libertad de culto solo se permiten como última ratio ${ }^{142}$. Igualmente cabe subrayar que la LEC dispone por sí misma los umbrales en virtud de los cuales se pueden activar determinadas medidas ${ }^{143}$. Por otra parte, las restricciones a la libertad de movimiento y la obligación de permanecer en casa fueron objeto de ponderadas regulaciones a lo largo del tiempo, por el efecto multiplicador que esas medidas irrogan. De un lado, tuvieron una cierta flexibilidad en términos comparativos (se admitían, por ejemplo, entre otras razones imperiosas, los deportes y actividades físicas al aire libre realizados en solitario, con los miembros de la propia familia o con otra persona) ${ }^{144}$. De otro, las restricciones a salir de casa durante determinadas franjas horarias o por concretos motivos solo podían aplicarse como última razón ${ }^{145}$.

d) Las cuestiones competenciales y de organización administrativa, en fin, han sido contempladas expresamente en la LCE y en las LPP ${ }^{146}$.

\section{UN BALANCE SOBRE EL PRINCIPIO DE LEGALIDAD EN LA LUCHA CONTRA LA PANDEMIA}

A nuestro limitado propósito, el recorrido por estos ordenamientos es suficiente para destacar dos observaciones ${ }^{147}$. Primera, que el principio de legalidad y la reserva de ley —en cuanto expresión de la democracia parlamentaria- se extienden a todos los aspectos relacionados con la lucha contra las enfermedades contagiosas, habida cuenta de la trascendencia de las cuestiones en juego

\footnotetext{
142 Art. 28.a(2).

143 Art. 28a(3). Anna-Bettina Kaiser y Roman Hensel, cit. en nota 120 núm. 30.

144 Ibid., núm. 59 y ss. Supra nota 27.

145 Ibid. Art. 28a(2) no 2).

146 Desde la atribución de nuevos poderes al Ministerio de Sanidad (Anna-Bettina Kaiser y Roman Hensel, cit. en nota 120 núm. 16, 36), hasta la coordinación federal de las medidas cuando se superen determinados umbrales (ibid., núm. 30, art. 28a.3); pasando por nuevas normas en materia de urbanismo en relación con las instalaciones para acoger a enfermos, o las funciones de las instituciones científicas (art. 4: Instituto Robert Koch).

147 Dejamos ahora fuera otras enseñanzas. Baste constatar, sin embargo, que la pertinaz omisión de las Cortes Generales en la lucha contra la COVID-19 no tiene paralelo en términos comparados: por todos, OxConLaw («Legal Response to Covid-19»). Asimismo, notas 40 y 49.

Respecto de países con un punto de partida y una estructura constitucional con ciertas analogías, como Portugal e Italia, es suficiente con notar aquí que el primero ha renovado al menos cada quince días durante el estado de emergencia la intervención parlamentaria, sin perjuicio de la aprobación de una ley específica; y en relación con el segundo que la configuración constitucional del decreto ley no padece del déficit democrático del nuestro (baste recordar el art. 70, párrafo primero, y el 77 de la Constitución italiana).
} 
(derechos fundamentales, fuentes, competencias...) ${ }^{148}$. Y, segunda, que el entendimiento que de tales principios se hace en el Reino Unido ${ }^{149}$ y en Alemania ${ }^{150}$ no es exótico o ajeno a nuestra cultura jurídica, sino que resulta de todo punto de vista exigible en nuestro ordenamiento jurídico ${ }^{151}$.

\section{LA QUIEBRA DEL PRINCIPIO DE LEGALIDAD Y DE LA RESERVA DE LEY EN EL ORDENAMIENTO ESPAÑOL EN LA LUCHA CONTRA LA COVID-19}

\section{LA AUSENCIA DE UNA LEY DE LUCHA CONTRA LAS ENFERMEDADES CONTAGIOSAS}

Ningún ordenamiento jurídico estaba suficientemente preparado, como se ha puesto de manifiesto en la incesante actividad legislativa a nivel mundial. El nuestro tampoco. Hay, sin embargo, dos diferencias notables con otros países de referencia: primera, nuestra infraestructura legal de partida cuando surge la pandemia, no una gripe estacional, era - y es— mucho más precaria, por no decir inexistente, en lo que hace a los poderes de emergencia sanitaria (ordinarios y extraordinarios); y, segunda, las Cortes Generales no han compensado ese déficit con un marco jurídico capaz de hacer frente a una situación de excepcionalidad histórica ${ }^{152}$.

148 Sean estas de derecho ordinario o del extraordinario, se refieran a las potestades ordinarias o a las extraordinarias, se trate de medidas singulares o generales y, en fin, a cualesquiera otras materias fundamentales conexas.

149 Nota 1.

${ }^{150}$ En síntesis, expresado en la doctrina de la esencialidad, en cuya virtud todas las cuestiones esenciales relacionadas con el ejercicio de, y las injerencias sobre, los derechos fundamentales han de ser reguladas mediante ley formal. Se trata de una genérica reserva de ley, que, de acuerdo con su Tribunal Constitucional, hunde sus raíces en el principio del estado de derecho y el principio democrático (reserva parlamentaria), que se extiende más allá de los derechos fundamentales. Esta doctrina se concreta en la propia Constitución (art. 80), al exigir unas condiciones para la habilitación legal de los reglamentos, así como su control. De la ley, en otras palabras, se ha de desprender cuál es el «programa» legal que el reglamento ha de alcanzar. Por lo demás, conocida es también la doctrina de la certeza y calidad de la ley parlamentaria.

151 Notas 3, 4, 41. Infra IV.1.

De acuerdo con tales criterios, no se acepta una cláusula habilitante como la que luce en el art. 3 de la Ley 3/1986, ni tan siquiera como precepto central para las (pocas) restricciones singulares de derechos fundamentales que en conjunción con otros preceptos puede soportar: notas 5 y 6 ; infra IV.1 y 2.

152 A juzgar por la proposición de ley orgánica de medidas especiales en materia de salud pública con el fin de controlar enfermedades transmisibles, presentada por grupo parla- 
Que el art. 3 de la Ley 3/1986 no es una ley contra las enfermedades contagiosas no requiere mayor análisis ${ }^{153}$. Hablar de "legislación sanitaria» —en materia de infecciones - no deja de ser un puro eufemismo ${ }^{154}$. La forzada comparación, deslizada en ocasiones, entre las leyes británicas y alemanas con nuestra legislación no requiere mayor comentario a la vista del análisis precedente.

\subsection{Inexistencia de una ley de enfermedades infecciosas que se active y conecte con el estado de alarma}

Como se ha notado, el Derecho extraordinario (en nuestro caso, el art. 116 CE y la LOAES) no cuenta con el apoyo y la colaboración de una regulación específica en materia de salud pública ${ }^{155}$. La respuesta a la COVID-19 se ha basado sustancialmente en reglamentos, que no implementan, nótese bien, una legislación primaria (por inexistente), sino que se aprueban por la autoridad competente sin referente legislativo ${ }^{156}$. Ello ha ocurrido en tiempos de alarma, bajo cuya declaración y cobertura se ha hecho necesario por tanto el dictado de las normas sanitarias correspondientes para cada tiempo y lugar. Y también ha sucedido sin alarma, sobre la ficción de que los pocos preceptos aislados de la legislación sanitaria constituirían, primero, una ley contra las enfermedades infecciosas y, además, una ley habilitadora y reguladora de potestades ordinarias y aun extraordinarias, siendo así que la pretendida conversión del insustancial art. 3 de la Ley 3/1986 en una «ley de plenos poderes» choca con todos los parámetros fundamentales ${ }^{157}$.

mentario de la oposición (BOCG, Congreso de los Diputados, B-161-1 de 23/04/2021, pág. 1), el entendimiento de la función legislativa, limitada a añadir unas pocas líneas a una Ley 3/1986 tan insustancial como obsoleta, está muy lejos de satisfacer las exigencias constitucionales.

153 La conclusión cabe hacerla extensiva a las leyes citadas en nota 5, aunque ofrezcan una mayor expresividad para actuaciones menores. No se olvide que para cumplir con la reserva de ley en materia de derechos fundamentales no basta con habilitar (expresamente) la injerencia, sino que ha de regularse el derecho afectado, las condiciones, el procedimiento, 154 Nota 5 . la organización y la competencia, la temporalidad, los controles... (véase supra III y V).

155 Es decir, no hay una regulación dentro de la propia LOAES, ni fuera de ella, a la que quepa remitirse mediante la declaración de alarma (I.1.2 y II.1).

156 No se trata, pues, de reglamentos ejecutivos, como es evidente.

157 Baste notar, por vía de síntesis, que las supuestas potestades de emergencia sanitaria que atribuiría no estarían sujetas a condición, requisito, procedimiento o criterio sustantivo alguno. Nada se dice en la Ley 3/1986 de la potestad reglamentaria de emergencia — si es genérica e indeterminada o se modula en función de la materia sobre la que verse-; de la vigencia temporal de esos reglamentos; del procedimiento de elaboración — siquiera sea de urgencia-; de la concreta autoridad que los pueda aprobar; de los límites sustantivos en relación con los derechos afectados (no es lo mismo imponer una distancia social que un 
Por consecuencia, los Ejecutivos han podido decidir libremente - sin directriz legislativa alguna, sea o no con la cobertura de la declaración del estado de alarma - si el objetivo era salvar vidas o evitar el colapso de las UCIs, por poner un ejemplo entre decenas ${ }^{158}$. El control judicial resulta en ese contexto poco menos que inasible - salvo que el Ejecutivo incurra en un patente "error del sistema» o de bulto- - ya que la medida queda a la pura creatividad de la autoridad $\mathrm{y}$ tiene en sede judicial un difícil contraste por falta de parámetros concretos ${ }^{159}$.

\subsection{Manifiesta insuficiencia del Derecho ordinario contra las enfermedades infecciosas}

Por decirlo en términos muy simples: tres preceptos legales ${ }^{160}$ no hacen una ley contra las enfermedades infecciosas, ni son capaces siquiera de representar una legislación reguladora de las potestades ordinarias, en la lucha contra enfermedades infecciosas. De ahí que solo haciendo una interpretación excesivamente expansiva del principio de legalidad (y de la reserva de ley), hasta romperlo virtualmente, pudo aceptarse, con la ayuda del art. 8.6 de la $\mathrm{LJCA}^{161}$, que el art. 3 de la Ley 3/1986 — y siempre y cuando se conecte con los otros dos preceptos en materia sanitaria ${ }^{162}$ - podría cubrir las restricciones singulares o individuales de los derechos fundamentales en las que pueda hallar algún apoyo expreso, nunca limitaciones generalizadas. Y ello porque, aun para una limitación singular de un derecho fundamental, una cláusula abierta como la que luce en el reiterado art. 3 Ley 3/1986 resulta inaceptable: en términos generales, tan solo cabría asumir una previsión indeterminada como broche de cierre de una larga relación de supuestos en los que se inserte y en cuyo contexto se interprete, pero no como una

horario de confinamiento y un cierre perimetral), ni de las típicas medidas de protección que pueden adoptarse; de cómo desplazan y en qué condiciones los reglamentos a las leyes, en qué manera se alteran las competencias... Sencillamente, porque no sirve, ni puede servir, para ello.

158 En contraste, por ejemplo, con la ley federal alemana, que se pronuncia expresamente por la conjunción de ambos objetivos y a tal fin establece los concretos umbrales que permiten la entrada en escena de las distintas medidas — art. 28.a(3)—.

159 Véase IV.2.

160 Nota 5.

161 El precepto disponía entonces, en el contexto de intervenciones singulares, como la autorización de entrada en domicilio, que «corresponderá a los Juzgados de lo Contencioso-administrativo la autorización o ratificación judicial de las medidas que las autoridades sanitarias consideren urgentes y necesarias para la salud pública e impliquen privación o restricción de la libertad o de otro derecho fundamental». Luego sería ligeramente modificado por la disposición final 2.1 de la Ley 3/2020, de 18 de septiembre, para ser aún más claro y para diferenciarlo de las medidas generales que la reforma procesal pretendió legitimar (supra II.2.2.c).

Nota 5. 
aislada habilitación genérica ${ }^{163}$, justamente para evitar, como ha ocurrido, que se convierta en un comodín ${ }^{164}$. Ha de insistirse, en fin, en que también el Derecho ordinario - a través de una ley contra las enfermedades infecciosas — ha de reunir ciertas garantías elementales.

\section{LA JURISPRUDENCIA DEL TRIBUNAL SUPREMO EN «CASACIÓN»SOBRE RATIFICACIÓN DE MEDIDAS DE CARÁCTER GENERAL}

a) De cuanto ha quedado dicho se impone por sí sola una severa crítica a la primera sentencia del Tribunal Supremo (TS) recaída en la nueva "casación» — de 24 de mayo de $2021^{165}$ _, que es de esperar sea revisada y superada, bien por el propio TS, o bien por el Tribunal Constitucional por más de un concepto ${ }^{166}$,

163 Véase nota 1 y núm. III. La polémica jurídica ha sido muy superior en otros países en supuestos de mucha menor indeterminación. Respecto de Alemania, si bien referido a la potestad reglamentaria, véase Anna-Bettina Kaiser y Roman Hensel, cit. en nota 120 núm. 25, 45-46. Allí el art. 28.1 LEC permite adoptar las «medidas de protección necesarias», aunque en un contexto y una delimitación de supuestos de hecho y consecuencias jurídicas de una notable densidad. En Italia, el Decreto Ley 6/2020, de 23 de febrero, preveía en su art. 1 una serie de medidas restrictivas sobre derechos (fundamentales y no fundamentales), que podrían adoptarse en caso de necesidad (la lista llega a establecer hasta 16 supuestos). Y en ese contexto se establece una cláusula abierta, mucho más cerrada que nuestro art. 3 de la Ley 3/1986: cuando exista un caso positivo que no pueda ser rastreado procedente de una zona ya afectada por el contagio de la COVID-19, las autoridades competentes deberán adoptar todas las medidas de contención y gestión que sean adecuadas y proporcionadas a la evolución de la situación epidemiológica. Y así y todo fue "fuertemente cuestionada», lo que motivó su derogación un mes después por Decreto Ley 19/2020, de 25 de marzo, si bien con algunos matices se ha mantenido en su conversión en ley de 5 de marzo de 2020, n. 13.

164 En definitiva, si normalizar un estado de alarma degradado y vacío de contenido resulta de todo punto indeseable, aún más lo es normalizar el ejercicio de potestades extraordinarias sin base jurídica (sin habilitación legislativa, ni declaración parlamentaria y sin regulación legal específica), o normalizar el ejercicio de potestades ordinarias, aunque estén referidas a medidas singulares, por carecer de ley, y que nos retrotraen muy atrás en el tiempo y nos alejan de países de referencia (véase en tal sentido la nota 153).

165 Tribunal Supremo, Sala de lo Contencioso-Administrativo, Sección Cuarta, Sentencia 719/2021. La sentencia hace frecuente remisión a los autos dictados el 20 de mayo de 2021; también al de 24 de marzo de 2021, de la Sección Primera, sobre los nuevos arts. 10.8 (y 11.1.i) LJCA.

Es, a nuestro juicio, una sentencia plana, que rehúye las cuestiones fundamentales, y que en su recorrido deja afirmaciones, en realidad un tanto apodícticas, poco convincentes, con efectos trascendentales, validando la abdicación parlamentaria a la que asistimos.

166 En primer término, desde luego, por la perniciosa doctrina sentada pro futuro sobre el principio de legalidad en general y la reserva de ley en particular, máxime en el ámbito de los derechos fundamentales (y no solo: I.2.2), y en el contexto de máxima tensión del ordenamiento. 
cuando concluye, en lo que ahora interesa, que la legislación sanitaria ${ }^{167}$ ofrece suficiente precisión para satisfacer la exigencia de certeza que ha de tener una ley para fundamentar las restricciones de los derechos fundamentales ${ }^{168}$.

b) Consistiendo la función del TS en esta clase de procedimiento, según la sentencia, en verificar en primer término la habilitación normativa ${ }^{169}$, cabría esperar una cadena argumental más sólida y una mejor defensa del principio de legalidad y de la reserva de ley ${ }^{170}$, que, en nuestro caso, han estado tutelados en ocasiones con más rigor por órganos jurisdiccionales inferiores.

El método y argumentación resultan planos y sin relieve. De entrada, reconoce que «se trata de saber si esas leyes, que no previeron circunstancias como las que estamos atravesando, permiten o no restringir la libertad de circulación que es la que viene en causa en este recurso ${ }^{171}$, lo cual debiera haber llevado a la inmediata conclusión de negarle todo fundamento y cobertura porque a los derechos

A ello se ańaden otros aspectos capitales que quedan fuera de nuestra consideración, tales como el grave problema constitucional que implica confiar a los jueces y tribunales, vía «ratificación», una función cuasi normativa, sobre la que ya existía cuestión de inconstitucionalidad planteada, y que el TS dice conocer pero que orilla por completo (implícitamente ha de entenderse que no existe para este duda positiva para plantear cuestión de inconstitucionalidad) (FJ 4); o el hecho, no menor de que este nuevo recurso de casación sea atribuido mediante decreto ley, que, por otra parte, decide desde cuándo puede interponerse, lo que permite influir sobre los casos que conoce.

Poco convincente, en fin, resulta el razonamiento sobre la naturaleza de esta modalidad de casación y sobre el interés casacional objetivo (FFJJ 4.C y 5.A). Las alegaciones que de contrario hace el Ministerio Fiscal, en particular su conclusión, son compartibles (FJ 3).

167 Nota 5.

168 Cfr. FJ 4.D. No advierte por otra parte que bajo su pretendida cobertura los Ejecutivos ejercen además potestades que van más allá de las limitaciones de los derechos fundamentales. Como se ha insistido, no todo versa, como sugiere la sentencia, sobre «la forma de prevenir la enfermedad [...] mediante medidas que comportan limitaciones de derechos fundamentales» (cfr. FJ 4.C): supra I.2.2.

169 El TS, afirma la sentencia, solo puede ejercer en este procedimiento de ratificación un juicio muy limitado, centrado primero en comprobar que existe la imprescindible habilitación normativa (FJ 4.B: habría de decirse mejor habilitación «legislativa»), ya que la ratificación —entendida como acto aprobatorio previo (FJ 4.A) — no la sustituye.

Hasta el punto de que el acuerdo de ratificación no impide el eventual y ulterior control pleno de la jurisdicción contencioso-administrativa. La ratificación no predetermina el fondo Cfr. FJ 4.B.

${ }^{170}$ La sentencia (FJ 4.D), antes de concluir que la suma de los tres artículos en liza (nota 5) satisface las exigencias constitucionales, se limita a hacer dos afirmaciones básicas: los derechos fundamentales no son absolutos y no toda restricción ha de operarse mediante ley orgánica. Afirmaciones de partida sin duda compartibles, pero que requieren un avance en relación con el caso planteado. Ese avance lo hace, en lo que a la ley orgánica se refiere, la siguiente STS, la 788/2021, de 3 de junio, en su FJ 7.

171 Cfr. FJ 4.D. 
fundamentales no se les puede restringir sin previsión legislativa, de modo implícito o supuesto, como aquí sucede. Ello no le impedirá, sin embargo, sostener que la restricción de la libertad de circulación tiene amparo en una disposición legal que no la ha previsto ${ }^{172}$.

La sentencia rebaja, en suma, los requerimientos del principio de legalidad y de la reserva de ley al nivel más bajo imaginable: dado que las tres disposiciones legales en cuestión ${ }^{173}$ no apoderan a la autoridad sanitaria "para cualquier cosa en cualquier momento» ${ }^{174}$, ese "conjunto de preceptos» ${ }^{175}$ ofrece "suficientes precisiones objetivas, subjetivas, espaciales, temporales y cualitativas para satisfacer las exigencias de certeza que han de tener los preceptos que fundamentan restricciones o limitaciones puntuales de derechos fundamentales» ${ }^{176}$, y, en concreto y sin mayores matices ${ }^{177}$, «de la libertad de circulación» ${ }^{178}$. En la misma línea, pero con

${ }^{172}$ Y ello mediante una doble sucesión argumental: las cláusulas abiertas no son un cheque en blanco — no permiten cualquier cosa, algunas directrices contienen-, de un lado y, de otro, las restricciones o limitaciones no se pueden predeterminar siempre (ibid.). Cabe compartir ambas afirmaciones. Lo que sucede es que de ellas no se sigue que las medidas restrictivas encuentren por ello la suficiente cobertura legal. Es cierto que la indeterminación legal no es total — la finalidad genérica de protección de la salud, la gravedad o la urgencia de las circunstancias están aludidas en la ley en cuestión-. Ello no significa, sin embargo, que la Ley 3/1986 cumpla con los parámetros de la reserva de ley (sea orgánica u ordinaria) que exige la citada STC 76/2019.

173 Recogidas en la sentencia. Son las que se citan en la nota $5 \mathrm{y}$ a las que se ha hecho referencia antes en IV.1.2.

${ }^{174}$ Cfr. FJ 4.B. En ello insiste después: los preceptos examinados no «adolecen de tal indeterminación que permitan hacer cualquier cosa a las Administraciones que los utilicen» (sic). Que existan algunas precisiones y no sean un referente normativo vacío de todo contenido no significa que cumpla las exigencias del principio de legalidad y de la reserva de ley (IV.1). Baste la comparación con los modelos enunciados en III.

175 FJ 4.D. Recuérdese que los tres preceptos hacen referencia primariamente, en línea con la tradición, a personas enfermas y en contacto con ellas (también a cosas e instalaciones vinculadas), y, por tanto, a medidas singulares. Supra I.2.3.

176 Se confunde, a nuestro juicio, la inexistencia de un «cheque en blanco» con la satisfacción del principio de legalidad y de la reserva de ley.

177 Habría de buscarse un nexo entre esos preceptos y la libertad de circulación (general). Habría que demostrar que estos preceptos autorizan a adoptar medidas generales para la población sana. Habría que explicar por qué estos reglamentos pueden desplazar a las leyes. Habría que argumentar por qué no ha de tener carácter orgánico la regulación legal de las restricciones de una libertad tan básica, de la que se siguen tantas otras, etc. Indemostrado queda, en fin, que de hecho los reglamentos en cuestión sean derecho ordinario.

178 FJ 4.D. Para convencer de que los tres preceptos legales en liza dan cobertura para lo que se está haciendo afirma que "no es una novedad que los tribunales deban extraer del ordenamiento jurídico los criterios para resolver problemas que no han recibido una solución precisa por parte del legislador» (FJ 4 in fine). Sin embargo, la interpretación judicial nunca suple las exigencias del principio de legalidad y de la reserva de ley. 
más crudeza aún y precisión en su alcance, se expresa una sentencia ulterior ${ }^{179}$, que considera que el art. 3 de la Ley 3/1986, por sí solo (y ya sin el auxilio de otros preceptos), da cobertura suficiente para extender las medidas restrictivas a personas sanas, es decir, a toda la colectividad ${ }^{180}$, y que consistan en el "toque de queda» o el límite máximo de personas en las reuniones familiares y sociales (con afectación de los derechos fundamentales de los arts. 18, 19 y $21 \mathrm{CE})^{181}$.

Sin embargo, y de contrario, cabe reiterar que una cosa es que quepan restricciones de derechos fundamentales fuera del estado de alarma y otra, muy distinta, que estas puedan establecerse al amparo de cláusulas genéricas que ninguna mención o referencia hacen a los derechos fundamentales y que, además y con toda obviedad, no están pensadas para afectar a toda la población. Las reglas interpretativas aquí son otras ${ }^{182}$. A la sentencia le falta además perspectiva: también el Derecho ordinario - en la lucha contra la enfermedad infecciosa- ha de reunir unas garantías elementales, que aquí no concurren ${ }^{183}$. El reglamento en el Derecho ordinario — en materias reservadas a la ley y más aún en el terreno de los derechos fundamentales - es ejecutivo o de desarrollo, no creativo e innovador; y, desde luego, no desplaza a las leyes: las implementa y aplica ${ }^{184}$.

c) La sentencia termina, en fin, con la admonición de que hubiera sido (solo) «deseable» (y no jurídicamente exigible) una regulación específica más detallada, en vez de "conceptos indeterminados» y "cláusulas generales» ${ }^{185}$. Y ello, dice, "para ofrecer la máxima seguridad jurídica»" ${ }^{186}$.

d) Por lo demás, y aunque la sentencia se cuida de explicitar que en este procedimiento judicial cabe «todo lo más... una verificación prima facie de la adecuación, necesidad y proporcionalidad de las medidas dispuestas»" ${ }^{187}$, lo cierto es que

179 STS 788/2021, de 3 de junio.

180 Ibid., FJ 6.

181 Ibid., FJ 7.

182 En resumen, no se entiende cómo el art. 3 de la Ley 3/1986 puede superar el test que la STC 76/2019, FJ 5, citada en la misma STS, establece en relación con la dimensión cualitativa que ha de cumplir la ley aquí. No se trata de determinar si el presupuesto de hecho de una norma reglamentaria menor es de aplicación — de modo innominado o implícito- a la fabricación de un producto industrial, sino de algo muy distinto. Supra III.3 y notas 3 y 4 .

${ }^{183}$ I.3, IV.1.2 in fine.

184 Ibid.

185 Elementos estos, sin duda, no equivalentes. Los conceptos indeterminados pueden ser respetuosos con los principios constitucionales aquí referidos. Las cláusulas generales, no (supra nota 1, III.3).

186 STS 719/2021, FJ 4.D. No es, sin embargo, un problema primariamente de seguridad jurídica, sino de legitimación democrática: infra $\mathrm{V}$.

187 Ibid., FJ 4.B. Ello lo dice, sin embargo, a los efectos de subrayar que aquí no se agotan las cuestiones de legalidad, ni las exigencias de la tutela judicial, por lo que la ratificación no 
el mecanismo de la «ratificación» — primero en los TSJ y ahora en el TS—, pretendido sucedáneo del déficit legislativo ( $\mathrm{y}$ democrático), ha conducido a sobredimensionar este principio (y con ello a banalizar el Estado de derecho), hasta el punto de inducir en muchos la idea de que, si es proporcionada una intervención, será por fuerza legítima. Se olvida así, primero y sobre todo, que la proporcionalidad constituye una pieza o garantía entre otras, y no la síntesis artificial de todas ellas ${ }^{188}$; segundo, que el test para determinar la desproporción en la ley (aún más que en su aplicación) solo en casos manifiestos puede dar positivo en sede jurisdiccional ${ }^{189} ; \mathrm{y}$, tercero, que por definición es un principio relativo, que no hace pronunciamientos absolutos sobre la injerencia en sí (ni por tanto fija criterios de una vez por todas), tanto porque mide la relación de medio a fin en cada caso y no en abstracto ${ }^{190}$ cuanto porque remite a hechos y circunstancias: una medida hoy puede ser proporcionada, y la misma, la próxima semana, en el mismo lugar, no serlo. En este contexto, resulta difícil, por decir lo menos, el encaje de este test en el molde de un recurso de casación y, con carácter más general, en la ratificación judicial ${ }^{191}$. Esta sentencia parece inscribirse a la postre en esa línea, en lugar de hacer frente a los vicios de ultra vires y de fortalecer los principios fundamentales

cierra las puertas a ulteriores recursos. Ahora bien, el control preventivo de la ratificación versa también sobre la proporcionalidad de las medidas sanitarias (STS 788/2021, de 3 de junio, FJ 5).

188 Una medida puede ser proporcionada y, sin embargo, suponer la lesión del contenido constitucionalmente garantizado, resultar contraria a los fines que el ordenamiento permite o incurrir en discriminación. Me remito a mi trabajo sobre «El principio de proporcionalidad. Estudio preliminar", Cuadernos de Derecho Público, 5, 1998, INAP, número monográfico sobre el principio de proporcionalidad, págs. 35 y ss., y, sobre todo, 42-43.

189 Lo que se pone de manifiesto también en este caso en el propio auto recurrido, con sus votos particulares, y las alegaciones de la recurrente (FJ 1 y 2) y en las acertadas alegaciones, a nuestro juicio, del Ministerio Fiscal (FJ 3).

${ }^{190}$ Lo cual presupone una nada fácil trabazón del término de comparación entre los medios restrictivos y sus fines inmediatos, vedando que cualquier medida limitadora se empareje con fines últimos y maximalistas del tipo "o se cierra el parque infantil», «se traza toda acción humana" $\mathrm{y}$ "se confina a toda la población» o "perecemos todos", por razones obvias, pues el miedo ha sido el más potente instrumento utilizado por el Estado autoritario. En sentido análogo, Lord Sumption, op. cit., nota 1. En igual sentido, ha razonado el Tribunal Constitucional alemán, en los primeros meses desde marzo de 2020. La relación de medio a fin se inscribe en una larga escalera, en la que el fin al que propende el medio objeto de examen será a su vez medio para otro fin más alto. La proporcionalidad requiere enjuiciar el medio con su fin inmediato.

191 Ello explica, por ejemplo, que el control judicial, más propio de una apelación, se derive hacia la suficiencia de la motivación o justificación de la medida, ante la imposibilidad de una unidad de doctrina en materia de proporcionalidad, como por cierto pretendía el recurrente (cfr. FJ 2). En igual sentido, la STS 788/2021, de 3 de junio, concluye que las medidas enjuiciadas no son proporcionadas (FJ 8), cuando en realidad quiere decir que no están suficientemente justificadas o motivadas, lo cual es distinto. 
y fundadores de nuestra democracia. En definitiva, margina problemas previos de trascendencia ${ }^{192}$, no se opone a la función cuasi normativa atribuida ${ }^{193}$ y deja sentada una doctrina extremadamente peligrosa ${ }^{194}$.

\section{UNA REFLEXIÓN FINAL. LA CRISIS DE LA DEMOCRACIA PARLAMENTARIA}

Habilitación y regulación de la acción sanitaria del Ejecutivo y la Administración contra la enfermedad constituyen la primera exigencia básica: no basta con la autorización legal (expresa y circunstanciada, naturalmente) de medidas restrictivas en el ámbito de los derechos fundamentales y en las materias aquí relacionadas; es necesario además establecer todos los referentes legislativos posibles — sustantivos, procedimentales, organizativos, de condiciones y límites- para enmarcar la actividad del Ejecutivo y de la Administración y permitir el control judicial y parlamentario. Es la hora del Ejecutivo, sí, pero no la hora del Ejecutivo absoluto.

La situación generada supone el mayor desconocimiento sistémico que han experimentado nuestra Constitución y los parámetros occidentales en que se sustenta. La misión del Parlamento no es puramente formal, ni es solo el lugar para la investidura. La misión del principio de legalidad y de la reserva de ley no es principalmente la de dotar de seguridad jurídica, preservar la división de poderes o hacer posible el control judicial (pues el juez lo es de la legalidad y no de vagas ideas de razonabilidad). Es, por encima de todo, la de hacer realidad la legitimación democrática del Ejecutivo y de la Administración. Y todo ello al servicio de, y en el respeto a, la persona y a su dignidad (arts. 1.1 y 10.1 CE).

El Ejecutivo deriva su poder del Parlamento, de la cámara electa, no directamente del pueblo. Sin el parlamento no habría democracia. Si las Cortes Generales no ejercen la potestad legislativa del Estado y no controlan la acción del Gobierno, abdicando de sus dos funciones esenciales, el Ejecutivo se absolutiza y la democracia se desvanece. Las Cortes están obligadas a legislar y el Gobierno a explicar y defender sus actuaciones. Como el pueblo carece de todo mecanismo institucional para pedir cuentas y controlar al Ejecutivo fuera del parlamento, la inacción de este implica una grave crisis de la democracia.

La mayor tensión que experimenta el Estado en su conjunto, la entera sociedad y el ordenamiento jurídico se da con el ejercicio de potestades extraordina-

192 Como los señalados en nota 166.

193 Tanto por razones de fondo (nota 45), como de forma (nota 166), y en las que ahora no cabe entrar. Véase la nota 178.

194 Un precepto abierto como el examinado serviría para otorgar tan amplios poderes al Ejecutivo en el futuro para hacer frente a cualquier otra crisis, sea o no sanitaria. 
rias. En medio de esta prueba, algunas instituciones no parecen haber estado a la altura. El derecho público que creíamos sobradamente enraizado ha mostrado profundas debilidades, una fragilidad alarmante.

El incumplimiento del deber de legislar ha llevado a forzar artificialmente los moldes del precario ordenamiento vigente en la lucha contra una pandemia histórica, en una auténtica operación de «ortopedia jurídica». Con todo, parece haberse aceptado ese punto de partida con cierta resignación. El debate se ha quedado en ocasiones en lo más básico y previo, en la búsqueda de una cobertura para restringir derechos fundamentales, obviando su regulación misma y otros impactos de suma trascendencia y tantas cuestiones capitales conexas. En ese contexto, no han faltado construcciones jurídicas que parecen asemejarse a una subasta a la baja. Los poderes de emergencia - cuya existencia no discute un Estado de derecho- no han de atribuirse (menos aún autoatribuirse) ni ejercerse a cualquier precio.

Resulta apremiante una ley contra las enfermedades infecciosas homologable con los países de referencia (y en un plano distinto una actualización del Derecho extraordinario del art. $116 \mathrm{CE}$ ), como también lo es la aprobación de procedimientos legislativos de urgencia para tiempos excepcionales, como han puesto en práctica tantos países, a fin de acabar con la masiva huida del Parlamento que supone el decreto ley en nuestro sistema (una epidemia desbordada y extendida también por las comunidades autónomas), y cuyo déficit democrático aún pasa desapercibido (bastaría compararlo con el decreto ley italiano para comenzar a apreciarlo). Es garantía última del principio democrático subyacente una posición institucional sólida de los jueces, tanto para rechazar actos y reglamentos sin base legislativa suficiente, que no respeten las fuentes del derecho o que supongan desplazamientos competenciales, como para oponerse al ejercicio de una función cuasi normativa. A ello podría coadyuvar —en la esfera política - una respuesta coordinada de los Ejecutivos autonómicos para evitar la complicidad y apremiar a las Cortes a aprobar la necesaria ley. Por lo demás, el déficit democrático en la lucha contra la pandemia es solo el último - y relevante- capítulo de un largo proceso de devaluación y crisis de la democracia parlamentaria. 
